\title{
GSK3 $\beta$ Impairs KIF1A Transport in a Cellular Model of Alzheimer's Disease but Does Not Regulate Motor Motility at S402
}

\author{
K.J. Gan, ${ }^{1}$ A. Akram, ${ }^{1, *}$ T.L. Blasius, ${ }^{4, *}$ E.M. Ramser, ${ }^{2}$ B.G. Budaitis, ${ }^{4,5}$ D.R. Gabrych, ${ }^{1}$ K.J. Verhey, ${ }^{4}$ and \\ (i)M.A. Silverman ${ }^{1,2,3}$
}

https://doi.org/10.1523/ENEURO.0176-20.2020

${ }^{1}$ Department of Molecular Biology and Biochemistry, Simon Fraser University, Burnaby, BC, V5A1S6, ${ }^{2}$ Department of Biological Sciences, Simon Fraser University, Burnaby, BC, V5A1S6, ${ }^{3}$ Centre for Cell Biology, Development and Disease, Simon Fraser University, Burnaby, BC, V5A1S6, ${ }^{4}$ Department of Cell and Developmental Biology, University of Michigan Medical School, and ${ }^{5}$ Program in Cellular and Molecular Biology, University of Michigan, Ann Arbor, Michigan, 94305

\begin{abstract}
Impairment of axonal transport is an early pathologic event that precedes neurotoxicity in Alzheimer's disease (AD). Soluble amyloid- $\beta$ oligomers (A $\beta$ Os), a causative agent of $A D$, activate intracellular signaling cascades that trigger phosphorylation of many target proteins, including tau, resulting in microtubule destabilization and transport impairment. Here, we investigated how KIF1A, a kinesin-3 family motor protein required for the transport of neurotrophic factors, is impaired in mouse hippocampal neurons treated with $\mathrm{A} \beta$ Os. By live cell imaging, we observed that $A \beta$ Os inhibit transport of KIF1A-GFP similarly in wild-type and tau knock-out neurons, indicating that tau is not required for this effect. Pharmacological inhibition of glycogen synthase kinase $3 \beta$ (GSK3 $\beta$ ), a kinase overactivated in $\mathrm{AD}$, prevented the transport defects. By mass spectrometry on KIF1A immunoprecipitated from transgenic AD mouse brain, we detected phosphorylation at S402, which conforms to a highly conserved GSK3 $\beta$ consensus site. We confirmed that this site is phosphorylated by GSK3 $\beta$ in vitro. Finally, we tested whether a phosphomimic of S402 could modulate KIF1A motility in control and A $\beta$ O-treated mouse neurons and in a Golgi dispersion assay devoid of endogenous KIF1A. In both systems, transport driven by mutant motors was similar to that of WT motors. In conclusion, GSK3 $\beta$ impairs KIF1A transport but does not regulate motor motility at S402. Further studies are required to determine the specific phosphorylation sites on KIF1A that regulate its cargo binding and/or motility in physiological and disease states.
\end{abstract}

Key words: Alzheimer's disease; amyloid beta oligomers; axonal transport; glycogen synthase kinase beta; kinesin-3 (KIF1A); motor protein phosphorylation

\section{Significance Statement}

Axonal transport of proteins and organelles is required for neuronal function and survival and is impaired in Alzheimer's disease (AD). Pathogenic mechanisms that directly impact motor protein motility before neuronal toxicity have not been widely investigated. Here, we show that KIF1A, the primary kinesin motor required for transport of neurotrophic factors, is impaired in mouse neurons treated with amyloid- $\beta$ oligomers (A $\beta$ Os), a causative agent of AD. Inhibition of glycogen synthase kinase $3 \beta$ (GSK3 $\beta$ ), a kinase overactivated in AD, prevents these defects. We detected phosphorylation of S402, a highly conserved GSK3 $\beta$ consensus site, in KIF1A immunoprecipitated from AD mouse brain. However, a phosphomimic of S402 did not modulate KIF1A motility in cell-based assays. Thus, GSK3 $\beta$ impairs KIF1A transport but likely not through phosphorylation at S402.

Received May 1, 2020; accepted October 8, 2020; First published October 16, 2020.

The authors declare no competing financial interests.
Author contributions: K.J.G., E.M.R., K.J.V., and M.A.S. designed research; K.J.G., A.A., T.L.B., E.M.R., and D.R.G. performed research; K.J.G., A.A., T.L.B., E.M.R., B.G.B., D.R.G., K.J.V., and M.A.S. analyzed data; K.J.G., K.J.V., and M.A.S. wrote the paper. 


\section{Introduction}

Neurons rely on microtubule-based, fast axonal transport of proteins and organelles for development, communication, and survival. Transport is driven by kinesin and cytoplasmic dynein motor proteins that carry cargoes anterogradely toward the synapse or retrogradely toward the cell body, respectively. Impaired motor-cargo binding and/or disrupted motor-microtubule interactions are common to several neurodegenerative diseases (Brady and Morfini, 2017). Importantly, they arise before neurite dystrophy, synapse loss, and cell death. In experimental models of Alzheimer's disease (AD), axonal transport of neuropeptide vesicles and mitochondria are perturbed by soluble amyloid- $\beta$ oligomers (A $\beta$ Os; Decker et al., 2010; Gan and Silverman, 2015; Seifert et al., 2016; Zhang et al., 2018), which accumulate in AD brain before detectable formation of $A \beta$ plaques and neurofibrillary tangles (Ferreira et al., 2015). A $\beta$ Os activate intracellular signaling cascades that lead to phosphorylation and aberrant activation of many target proteins, including the microtubule-associated protein tau (Cline et al., 2018). Although much research has focused on tau hyperphosphorylation and on subsequent microtubule destabilization and cytoskeletal collapse that halt transport in advanced stages of $A D$, it fails to account for earlier, subtler and potentially reversible mechanisms that modulate transport independent of tau. Thus, we focused our investigation on $\mathrm{A} \beta \mathrm{O}$-activated kinases that might directly impair motor protein activity.

AD-associated kinases phosphorylate kinesin-I (KIF5) and thereby impair motility and cargo binding (Gibbs et al., 2015; Brady and Morfini, 2017); however, it is unknown whether they regulate the kinesin-3 motor, KIF1A. KIF1A associates with several different membranous organelles such as dense core vesicles (DCVs), which contain critical signaling molecules including brain-derived neurotrophic factor (BDNF; Yonekawa et al., 1998; Lo et al., 2011; Kondo et al., 2012; Hung and Coleman, 2016).

This work was supported by a Natural Sciences and Engineering Research Council of Canada (NSERC) doctoral scholarship and the CD Nelson graduate scholarship (Simon Fraser University; to K.J.G.), the National Institutes of Health (NIH) Cellular and Molecular Biology Training Grant T32-GM007315 (to B.G.B.), the National Science Foundation Graduate Research Fellowship 1256260 (to B.G. B.), a Rackham Predoctoral Fellowship from the University of Michigan (B.G. B.), NIH Grants R01GM070862 and R35GM131744 (to K.J.V.), the NSERC Grant RGPIN-2018-03945 (to M.A.S.), and the Canadian Institutes of Health Research Grant 90396 (to M.A.S.).

${ }^{*}$ A.A. and T.L.B. contributed equally to this work.

K. J. Gan's present address: Department of Molecular and Cellular Physiology, Stanford University School of Medicine, Stanford, CA, 94305

Acknowledgements: We thank T. Tomiyama (Osaka City University) for providing our lab with Tg2576 AD (APPSwe) and wild-type mouse brains. We also thank M. Shakeri (Simon Fraser University) for assistance with experiments and C. Krieger (Simon Fraser University), S. Pelech (Kinexus, Vancouver, BC), D. Smith (University of Victoria, Proteomics Centre), and S. Niwa (Tohoku University) for general discussions and comments on this manuscript.

Correspondence should be addressed to M.A. Silverman at masilver@ sfu.ca or K.J. Gan at kgan8@stanford.edu.

https://doi.org/10.1523/ENEURO.0176-20.2020 Copyright (C 2020 Gan et al.

This is an open-access article distributed under the terms of the Creative Commons Attribution 4.0 International license, which permits unrestricted use, distribution and reproduction in any medium provided that the original work is properly attributed.
Despite the importance of BDNF in neuronal physiology and its reduced availability in $A D$ and other neurodegenerative diseases (Mariga et al., 2017), mechanisms that regulate its transport by KIF1A are unclear. Previously, Decker et al. (2010) demonstrated that $A \beta O$ s impair axonal BDNF transport in primary hippocampal neurons. Contrary to a current model (Bloom, 2014), these transport defects are induced independent of tau, microtubule destabilization, and acute cell death (Ramser et al., 2013). Furthermore, in these studies, BDNF transport impairment was prevented by inhibiting glycogen synthase kinase $3 \beta($ GSK $3 \beta)$, a kinase that is implicated in many aspects of AD pathogenesis (Maqbool et al., 2016) and regulates kinesin-1 interactions with cargo and microtubules (Morfini et al., 2002; Weaver et al., 2013). Whether $\mathrm{A} \beta \mathrm{O}$-induced dysregulation of GSK3 $\beta$ signaling directly affects KIF1A motility has not been investigated.

Here, we show by live cell imaging that $A \beta O$ s impair KIF1A motility in wild-type (WT) and tau knock-out hippocampal neurons, indicating that tau is not required for KIF1A transport disruption. Pharmacological inhibition of GSK3 $\beta$ prevents these defects, and GSK3 $\beta$ coimmunoprecipitates with KIF1A, indicating that this kinase may regulate motility. By mass spectrometry (MS) on KIF1A isolated from $A D$ mouse brain, we identified several phosphopeptides targeted by kinases associated with $A D$, including GSK3 $\beta$. We discovered that S402, located proximal to the neck-coil domain, conforms to a highly conserved GSK3 $\beta$ consensus site and hypothesized that it might regulate KIF1A processivity. Thus, we tested whether a phosphomimic of S402 could modulate KIF1A motility in mouse neurons and in a Golgi dispersion assay devoid of endogenous KIF1A (Engelke et al., 2016; Budaitis et al., 2019). In both systems, we did not observe any alterations in the motility of KIF1A. Further studies will be required to determine whether other phosphorylation sites on KIF1A regulate its motility or binding to DCVs in physiological and AD states.

\section{Materials and Methods}

\section{Hippocampal cell culture and expression of transgenes}

Primary hippocampal neurons from embryonic day $(\mathrm{E}) 16$ WT and tau knock-out mice of either sex (The Jackson Laboratory) were cultured as described previously (Kaech and Banker, 2006) and kept in PNGM primary neuron growth media (Lonza). The glial feeder layer was derived from murine neural stem cells as described previously (Miranda et al., 2012). At 10-12 d in vitro (DIV), cells were cotransfected using Lipofectamine 2000 (Invitrogen) with plasmids encoding soluble blue fluorescent protein ( $\mathrm{pmU} \beta \mathrm{A}$ eBFP) and mouse KIF1A-GFP (GW1-KIF1A-eGFP; Lee et al., 2003). Cells expressed constructs for $36 \mathrm{~h}$ before live imaging of KIF1A transport. All experiments with animals were approved by and followed the guidelines set out by the University Animal Care Committee, Protocol 1261B-05.

\section{$A \beta O$ and GSK3 $\beta$ Inhibitor VIII treatments}

Soluble, full-length $A \beta$ 1-42 peptides (American Peptide) were prepared exactly according to the method of Lambert 
et al., 2007 (Lambert et al., 2007) and applied to cells at a final concentration of $500 \mathrm{~nm}$ for $18 \mathrm{~h}$. Cells were incubated with $5 \mu \mathrm{M}$ GSK3 $\beta$ Inhibitor VIII (Calbiochem) or equivalent volumes of vehicle $(\mathrm{EtOH}) 30 \mathrm{~min}$ before $\mathrm{A} \beta \mathrm{O}$ or vehicle treatment.

\section{Live imaging and analysis of KIF1A transport}

KIF1A-GFP transport was analyzed using a standard wide-field fluorescence microscope equipped with a cooled charge-coupled device camera and controlled by MetaMorph (Molecular Devices) as described previously (Kwinter and Silverman, 2009; Gan and Silverman, 2016). All imaging, typically 100 frames, was recorded by the "stream acquisition module" in MetaMorph. Briefly, cells were sealed in a heated imaging chamber, and recordings were acquired from double transfectants at an exposure time of $250 \mathrm{~ms}$ for $90 \mathrm{~s}$. This captured dozens of transport events per cell in 100- $\mu \mathrm{m}$ segments of the axon. Dendrites and axons were initially identified based on morphology and confirmed retrospectively by immunostaining against MAP2, a dendritic cytoskeletal protein. Soluble BFP detection was necessary to determine the orientation of the cell body relative to the axon and thus to distinguish between anterograde and retrograde transport events. Motor protein flux, velocity, and run lengths were obtained through tracing kymographs in MetaMorph. Flux is the summation of distances traveled by all moving KIF1A puncta standardized by the length of axon imaged and duration of each movie (in microminutes): $\frac{\sum_{i=1}^{n} d_{i}}{1 \times t}$ where $d$ are the individual KIF1A run lengths, $l$ is the length of axon imaged and $t$ is the duration of the imaging session. A KIF1A punctum was defined as undergoing a directed run if it traveled a distance of $\geq 2 \mu \mathrm{m}$. This distance was determined as a safe estimate of the limit of diffusion based on the assumption that root-mean-squared displacement equals $\sqrt{2 D t}$, where $D$ is the diffusion coefficient $\left(D=0.01 \mu \mathrm{s}^{2} / \mathrm{s}\right.$ for the KIF1A cargo of DCVs) and $t$ is the duration of the imaging period ( $t=50 \mathrm{~s}$; Abney et al., 1999; Gan and Silverman, 2016). A run was defined as terminating if the vesicle remained in the same position for at least four consecutive frames. Percentage flux represents the flux in treated neurons normalized to controls (100\%). Statistical analyses were performed using Microsoft Excel or GraphPad Prism. Data are presented as mean \pm SEM. Significant differences between treatments were analyzed by $t$ tests with equal or unequal variance at a $95 \%$ confidence interval. For live imaging experiments, a minimum of 15 cells from three independent cultures $(n=3)$ were analyzed.

\section{KIF1A immunoprecipitation and GSK3 $\beta$ immunoblotting}

Primary hippocampal neurons from E16 WT C57BI/6 mice (The Jackson Laboratory) were lysed in ice-cold radioimmunoprecipitation assay (RIPA) buffer ( $50 \mathrm{~mm}$ Tris; pH 7.5, 5 mм EDTA, 150 mm NaCl, 1\% Triton X-100) containing cOmplete protease inhibitor cocktail (Roche), Halt phosphatase inhibitor cocktail (ThermoFisher), $1 \mathrm{~mm}$ phenylmethylsulfonyl fluoride (PMSF), and $1 \mathrm{~mm}$ orthovandate. A total of $500 \mu \mathrm{g}$ of lysate was mixed overnight at $4^{\circ} \mathrm{C}$ with $12 \mu \mathrm{g}$ of KIF1A antibody (BD Transduction Laboratories; catalog \#612094). Samples were then combined with $50 \mu \mathrm{l}$ of Protein A/G-agarose (Santa Cruz Biotechnology; catalog \#sc-2003) beads and mixed at $4{ }^{\circ} \mathrm{C}$ for $3 \mathrm{~h}$. Samples were gently pelleted and rinsed three times with RIPA buffer. The immunoprecipitated proteins $(5-10 \mu \mathrm{g})$ were resolved on $10 \%$ SDS-PAGE gels and transferred to polyvinylidene difluoride (PVDF) membranes. Membranes were probed with anti-KIF1A (1:1000, BD Transduction Laboratories; catalog \#612094) and anti-GSK3 $\beta$ (1:000, Cell Signaling Technology; catalog \#27C10) overnight at $4^{\circ}$ C. Immunoreactive bands were visualized using enhanced chemiluminescent substrate (ThermoFisher Scientific) for detection of peroxidase activity from horseradish peroxidase (HRP)-conjugated antibodies.

To detect total KIF1A phosphorylation, C57BI/6 adult mouse hippocampi (six) were homogenized and lysed in ice-cold RIPA buffer containing cOmplete protease inhibitor cocktail (Roche), Halt phosphatase inhibitor cocktail (ThermoFisher), $1 \mathrm{~mm}$ PMSF, and $1 \mathrm{~mm}$ orthovandate. $500 \mu \mathrm{g}$ of lysate was mixed overnight at $4^{\circ} \mathrm{C}$ with $12 \mu \mathrm{g}$ of KIF1A antibody (BD Transduction Laboratories; catalog \#612094). Samples were then combined with $50 \mu \mathrm{l}$ of Protein A/G-agarose (Santa Cruz Biotechnology; catalog \#sc-2003) beads and mixed at $4^{\circ} \mathrm{C}$ for $3 \mathrm{~h}$. Samples were gently pelleted and rinsed three times with RIPA buffer. The immunoprecipitated proteins $(5-10 \mu \mathrm{g})$ were resolved on $10 \%$ SDS-PAGE gels and transferred to PVDF membranes. Membranes were probed with an anti-phosphoserine monoclonal antibody 7F12 (1:2000, Invitrogen) and an anti-phosphothreonine monoclonal antibody PT-5H5 (1:2000, Invitrogen) overnight at $4^{\circ} \mathrm{C}$. Immunoreactive bands were visualized using enhanced chemiluminescent substrate (SuperSignal West Pico PLUS Chemiluminescent Substrate, ThermoFisher Scientific) for detection of peroxidase activity from HRP-conjugated secondary antibodies.

To determine the presence of KIF1A in COS7 cells, total protein isolated from cell lysates $(15 \mu \mathrm{g})$ were separated on a precast $4-15 \%$ gradient gel (Bio-Rad Laboratories) and subsequently transferred to a PVDF membrane. Membranes were blocked using a 3\% BSA solution in TBS-Tween and blotting was performed using primary antibodies in blocking solution against KIF1A (1:500; BD Transduction Laboratories) and the loading control, GAPDH (1:1000; Novus Biologicals; catalog \#NB300327). Immunoreactive bands were visualized using enhanced chemiluminescent substrate (SuperSignal West Pico PLUS Chemiluminescent Substrate: ThermoFisher Scientific) for detection of peroxidase activity from HRPconjugated secondary antibodies. Blotting was performed in triplicate using two different cell lysate samples.

\section{Tandem MS (MS/MS) and KIF1A phosphosite analysis}

KIF1A was immunoprecipitated from 14-month-old Tg2576 AD (APPSwe) and age-matched WT control mouse brains that were provided by T. Tomiyama (Osaka City University, Japan). Cortices from three brains of each genotype were first homogenized in standard RIPA buffer 
with 1\% NP-40 including cOmplete protease inhibitor cocktail (Roche), Halt phosphatase inhibitor cocktail (ThermoFisher), $1 \mathrm{~mm}$ PMSF, and $1 \mathrm{~mm}$ orthovandate in a Retsch Mixer Mill 301. Lysates were cleared of insoluble material by centrifugation at $14,000 \times g$ for $10 \mathrm{~min}$ at $4^{\circ} \mathrm{C}$ and then incubated with $3.5 \mu \mathrm{g}$ of anti-KIF1A (BD Transduction Laboratories; catalog \#612094) for $3 \mathrm{~h}$ at $4^{\circ} \mathrm{C}$ using constant rotation. Subsequently, $40 \mu \mathrm{l}$ of Protein A/G PLUS-agarose beads (Santa Cruz Biotechnology; catalog \#sc-2003) were added and incubated for another $3 \mathrm{~h}$ at $4^{\circ} \mathrm{C}$ using constant rotation. Immune complexes were washed with $1 \times$ RIPA with $0.5 \mathrm{M} \mathrm{NaCl}$ and pelleted, followed by a second wash using $2 \times$ RIPA with $140 \mathrm{~mm}$ $\mathrm{NaCl}$. A total of $5 \mu \mathrm{g}$ of each sample was heated to $95^{\circ} \mathrm{C}$ in $2 \times$ Laemmli buffer containing $100 \mathrm{~mm}$ DTT and resolved on a $10 \%$ SDS-PAGE gel. Coomassie-stained protein bands were excised from the SDS-PAGE gel, digested with trypsin, and used for $\mathrm{MS} / \mathrm{MS}$ with $\mathrm{TiO}_{2}$ enrichment for phosphopeptides (University of Victoria Genome BC Proteomics Centre). MS was performed twice on each sample. KIF1A phosphorylation from Tg2576 and WT brain were compared using the algorithm PhosphoRS, which calculates the probability of each phosphorylation site within a peptide. GSK3 $\beta$ phosphosites were identified by comparison to existing sequences within the Phosida (phosida.com) and Phosphonet (https://kinexus.ca) databases.

\section{Details of MS protocol}

In gel trypsin digestion

Gel slices were manually cut into $1-\mathrm{mm}$ cubes and Coomassie Blue gel cubes de-stained (50/45/5 v/v methanol/water/acetic acid). Gel cubes were washed with water and $200 \mathrm{~mm}$ ammonium bicarbonate before reduction (10 mm dithiothreitol, Sigma) $30 \mathrm{~min}$ at room temperature and alkylation (100 mm iodoacetamide, Sigma) $30 \mathrm{~min}$ at room temperature. Modified sequencing grade porcine trypsin solution $30 \mu \mathrm{l}(20 \mathrm{ng} / \mu \mathrm{l}$, Promega) was added to the gel slice enzyme/protein ratio 1:50 and then digested for $16 \mathrm{~h}$ at $37^{\circ} \mathrm{C}$. The peptides were extracted out of the gel slices with $400 \mu \mathrm{l}(60 / 39 / 1 \mathrm{v} / \mathrm{v}$ acetonitrile/water/trifluoracetic acid). The sample was then speed vac centrifuged and stored at $-80^{\circ} \mathrm{C}$ until analysis.

\section{Titanium dioxide phosphopeptide enrichment}

$\mathrm{TiO}_{2}$ binding buffer $[70 \% \mathrm{v} / \mathrm{v}$ acetonitrile, $5 \% \mathrm{v} / \mathrm{v}$ trifluoroacetic acid (TFA), containing $300 \mathrm{mg} / \mathrm{ml}$ lactic acid] was added to $80 \%$ of each sample digest along with $10 \mathrm{mg}$ of $\mathrm{TiO}_{2}$ beads (GL Science, $10 \mu \mathrm{m}$ in diameter). Samples were incubated with $\mathrm{TiO}_{2}$ with end-over-end rotation for $90 \mathrm{~min}$ at $25^{\circ} \mathrm{C}$. After incubation, $\mathrm{TiO}_{2}$ beads were transferred to homemade StageTip with $\mathrm{C}_{8}$ frit for phosphopeptide elution. The beads were washed $4 \times 50 \mu \mathrm{TiO}_{2}$ binding buffer, and $4 \times 50 \mu \mathrm{l}$ buffer $\mathrm{B}(80 \%$ $\mathrm{ACN}, 0.1 \% \mathrm{TFA}$ ). Elution was performed with the following steps: $50 \mu \mathrm{l} 0.5 \% \mathrm{NH}_{4} \mathrm{OH}, 50 \mu \mathrm{l} 0.5 \% \mathrm{NH}_{4} \mathrm{OH} / 30 \%$ $\mathrm{ACN}$, and $50 \mu \mathrm{l} 0.5 \% \mathrm{NH}_{4} \mathrm{OH} / 50 \% \mathrm{ACN}$. The eluent from the three elutions was pooled and formic acid $(20 \mu \mathrm{l})$ was added to lower the $\mathrm{pH}$. The samples were frozen at $-80^{\circ} \mathrm{C}$ and lyophilized to dryness before liquid chromatography (LC)-MS analysis.

\section{LC-MS/MS analysis}

The peptide mixtures were separated by on-line reversed phase chromatography using a Thermo Scientific EASY-nLC II system with a reversed-phase pre-column Magic C-18AQ (100- $\mu \mathrm{m}$ I.D., 2-cm length, $5 \mu \mathrm{m}, 100 \AA$, Michrom BioResources Inc) pre-column and a reversed phase nano-analytical column Magic C-18AQ $(75-\mu \mathrm{m}$ I.D., $15-\mathrm{cm}$ length, $5 \mu \mathrm{m}, 100 \AA$, Michrom BioResources Inc) both in-house prepared, at a flow rate of $300 \mathrm{nl} / \mathrm{min}$. The chromatography system was coupled to an LTQ Orbitrap Velos mass spectrometer equipped with a Nanospray II source (ThermoFisher Scientific). Solvents were A: $2 \%$ acetonitrile, $0.1 \%$ formic acid; B: $90 \%$ acetonitrile, $0.1 \%$ formic acid. After a 249 bar $(\sim 5 \mu l)$ pre-column equilibration and 249 bar $(\sim 8 \mu l)$ nanocolumn equilibration, samples were separated by a 55 -min gradient $(0 \mathrm{~min}$ : $5 \% \mathrm{~B}$; 45 min: $45 \% B$; 2 min: $80 \% B$; 8 min: $80 \% B)$. The LTQ Orbitrap Velos (ThermoFisher Scientific) parameters were as follows: nano-electrospray ion source with spray voltage $2.2 \mathrm{kV}$, capillary temperature $225^{\circ} \mathrm{C}$. Survey MS1 scan $\mathrm{m} / \mathrm{z}$ range $400-2000$ profile mode, resolution 60,000 at $400 \mathrm{~m} / \mathrm{z}$ with $A G C$ target $1 \mathrm{E} 6$, and one microscan with maximum inject time $200 \mathrm{~ms}$. Lock mass Siloxane 445.120024 for internal calibration with preview mode for FTMS master scans: on, injection waveforms: on, monoisotopic precursor selection: on; rejection of charge state: 1. The eight most intense ions charge state $2-4$ exceeding 5000 counts were selected for CID ion trap MSMS fragmentation (ITMS scans 2-9) and detection in centroid mode. Dynamic exclusion settings were: repeat count: 2; repeat duration: $15 \mathrm{~s}$; exclusion list size: 500 ; exclusion duration: $60 \mathrm{~s}$ with a $10 \mathrm{ppm}$ mass window. The CID activation isolation window was: $2 \mathrm{Da}$; AGC target: $1 \mathrm{E} 4$; maximum inject time: $25 \mathrm{~ms}$; activation time: $10 \mathrm{~ms}$; activation Q: 0.250 ; and normalized collision energy $35 \%$.

\section{Data analysis parameters}

Raw files were analyzed with Proteome Discoverer 1.3.0.339 software suite (Thermo Scientific). Parameters for the Spectrum Selection to generate peak lists of the CID spectra (activation type: CID; s/n cutoff: 1.5 ; total intensity threshold: 0; minimum peak count: 1 ; precursor mass: $350-5000 \mathrm{Da}$ ) The peak lists were submitted to an in-house Mascot 2.2 against the Uniprot-Swissprot 20110104 (523,151 sequences; 184,678,199 residues) Allspecies taxonomy and Mouse only database as follows: precursor tolerance $8 \mathrm{ppm}$; MS/MS tolerance $0.6 \mathrm{Da}$; Trypsin enzyme 1 missed cleavages; FT-ICR ESI instrument type; fixed modification: carbamidomethylation $(C)$; variable modifications: deamidation $(\mathrm{N}, \mathrm{Q})$; oxidation (M), propionamide (C), and phosphorylated (T, Y, S). Percolator settings: $\max \delta$ Cn 0.05 ; target FDR strict 0.01 , target FDR relaxed 0.05 with validation based on $q$ value.

Additional searches were performed against IPI_mouse 3_47 (110 771 sequences; 49,890,456 residues). 


\section{In vitro phosphorylation assay}

An in vitro phosphorylation assay was designed to assess the role of phosphorylation on S402. In this radiometric assay, three different proline directed kinases, cyclin-dependent kinase 2 (CDK2), extracellular signalregulated kinase 2 (ERK2), and GSK3 $\beta$, were tested for their ability to phosphorylate the S402 residue on KIF1A by the Kinexus substrate profiling services (Vancouver, $\mathrm{BC}$ ). The various recombinant protein kinases employed in the substrate profiling process were cloned, expressed and purified using proprietary methods. Quality control testing is routinely performed on each of the kinases to ensure compliance to acceptable standards. The $\left[\gamma-{ }^{33} \mathrm{P}\right]$ ATP was purchased from PerkinElmer. All other materials were of standard laboratory grade. A total of $2 \mathrm{mg}$ of each peptide was synthesized based on a peptide sequence of interest as listed below:

1. KSP04-CAF KIF1A [S402] WT KKALVGMSPSS-pS-L $>98 \%$

2. KSP04-CBT KIF1A [A402] mutant (MT) KKALVGMAPSSpS-L $>98 \%$.

\section{Inducible Golgi dispersion assay}

The rat KIF1A(FL)-V483N coding sequence (Soppina et al., 2014) was tagged with monomeric NeonGreen and an FRB domain. Mutations of S411E and S411A were introduced by QuikChange mutagenesis. Plasmids for expression of WT or mutant motors were cotransfected into COS-7 cells with a plasmid for expression of GMAP210mRFP-2xFKBP at a ratio of 6:1 with TransIT-LT1 transfection reagent (Mirus). Sixteen hours after transfection, rapamycin (Calbiochem, Millipore Sigma) was added to a final concentration of $44 \mathrm{~nm}$ to promote FRB and FKBP heterodimerization and recruitment of motors to the Golgi. After $30 \mathrm{~min}$, the cells were fixed with $3.7 \%$ formaldehyde (ThermoFisher Scientific) in 1× PBS for $10 \mathrm{~min}$, quenched in $50 \mathrm{~mm}$ ammonium chloride in PBS for $5 \mathrm{~min}$, permeabilized with $0.2 \%$ Triton $\mathrm{X}-100$ in PBS for $10 \mathrm{~min}$, and then incubated in blocking buffer $(0.2 \%$ fish skin gelatin in PBS). Primary [polyclonal antibody against cis-Golgi marker giantin (1:1200 PRB-114C, Covance)] and secondary antibodies [Alexa Fluor 680-labeled goat anti-rabbit (1:500, Jackson ImmunoResearch) and DAPI (final concentration $10.9 \mu \mathrm{M})$ ] were added to blocking buffer and incubated for $1 \mathrm{~h}$ each at room temperature. Coverslips were mounted in ProlongGold (Invitrogen) and imaged using an inverted epifluorescence microscope (Nikon TE2000E) with a $40 \times 0.75 \mathrm{NA}$ objective and a CoolSnapHQ camera (Photometrics).

Golgi localization before and after motor recruitment was quantified using a distance-based analysis using a custom ImageJ plugin (Budaitis et al., 2019) for $N \geq 26$ cells across two independent experiments. Briefly, (1) a custom ImageJ plugin generates a line scan from the centroid of the nucleus to the periphery of the cell; this is repeated every one degree for a total of 360 linescans around the cell. The fluorescence intensity along each line scan is determined. (2) For background subtraction, a line scan starting from the centroid of the nucleus to the cell periphery is generated in a region of the cell that lacks cargo and is subtracted from each line scan (scaled background subtraction). Distances that correspond to regions inside the nucleus are removed from each line scan, such that point 0 corresponds to the edge of the nuclear membrane. Oversampling of pixels in the center of the cell was corrected, following the assumption that the cell is a perfect circle. (3) The total distance of each line scan was normalized to itself, such that the distance of each line scan was between 0 (nuclear membrane) and 1 (cell periphery). (4) Pixel intensities were grouped in bins by distance (width, 0.05) and only the top 200 pixels within each bin were included in further analysis. (5) Pixel intensity was averaged for each binned distance to generate a dispersion profile for the cell.

\section{Statistical analyses}

Statistical analyses were performed using Microsoft Excel or GraphPad Prism. For KIF1A live imaging experiments in hippocampal neurons, motor protein flux is presented as mean \pm SEM. All experiments were performed on at least 15 cells from three independent cultures. All statistical analyses were performed using one-way ANOVAs with Tukey's post hoc tests, comparing control and treated conditions within the same experiments. For inducible Golgi dispersion assays, the fluorescence intensity for each normalized distance bin was averaged across all cells in two independent experiments and the data were plotted as mean \pm SEM. The statistical differences in mean fluorescence intensity were calculated at each binned distance comparing the WT and MT motor for each condition (-Rap and + Rap) using a two-tailed unpaired Student's $t$ test. Differences between the WT and MT motors at $p<0.05$ are indicated by an asterisk. WT Rap, $n=26$ cells; WT + Rap, $n=31$ cells; S411A - Rap, $n=30$ cells; S411A + Rap, $n=29$ cells; S411E - Rap, $n=27$ cells; S411E + Rap, $n=28$ cells.

\section{Results}

\section{A 30 s impair KIF1A transport independent of tau}

Previously, Ramser et al. (2013) discovered that $A \beta$ Os disrupt BDNF transport independent of tau hyperphosphorylation, microtubule destabilization, and neuronal toxicity. These findings raised the intriguing possibility that KIF1A, the primary kinesin motor required for BDNF transport (Barkus et al., 2008; Lo et al., 2011; Kondo et al., 2012), is directly impaired in $\mathrm{A} \beta \mathrm{O}$-treated neurons by a mechanism independent of tau. In the present study, we cultured hippocampal neurons from WT $\left(\mathrm{tau}^{+/+}\right)$and tau knock-out $\left(\mathrm{tau}^{-/-}\right)$mice, expressed mouse KIF1A tagged with enhanced green fluorescent protein (KIF1A-eGFP) in these neurons at $10 \mathrm{DIV}$, and added vehicle solution (control) or $500 \mathrm{~nm} \mathrm{~A} \beta$ Os to their culture medium at 11 DIV (Fig. 1A). Irreversible $\mathrm{A} \beta \mathrm{O}$ binding was confirmed retrospectively by immunocytochemistry (Fig. 1B) using an oligomer-selective antibody (NU-4; Lambert et al., 1998). After $18 \mathrm{~h}$ of treatment, we imaged KIF1A-eGFP transport and compared the flux, velocity, and run length of axonal KIF1A puncta across all conditions (Fig. 1C; Table 1). 
A Timeline of Imaging Experiments

\begin{tabular}{|c|c|c|c|c|}
\hline & $\begin{array}{l}\text { Transfect neurons with } \\
\text { BFP and KIF1A-GFP }\end{array}$ & $\begin{array}{l}\text { Add } \\
\text { AßOs }\end{array}$ & $\begin{array}{l}\text { Image } \\
\text { Neurons }\end{array}$ & $\begin{array}{c}\text { Retrospective } \\
\text { Immunocytochemistry }\end{array}$ \\
\hline Culture neurons & 10-12 & 13 & 14 & \\
\hline
\end{tabular}

B Expression of KIF1A-GFP in an A 30 treated neuron
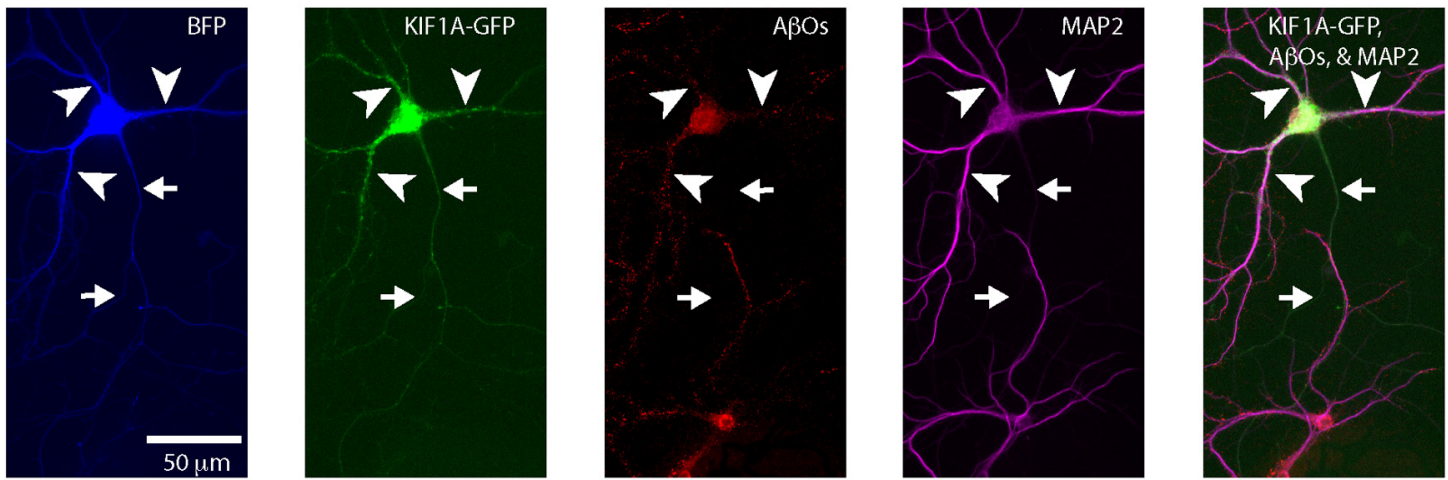

C Chemical Inhibition of GSK3 $\beta$ prevents $A \beta O$-induced transport defects

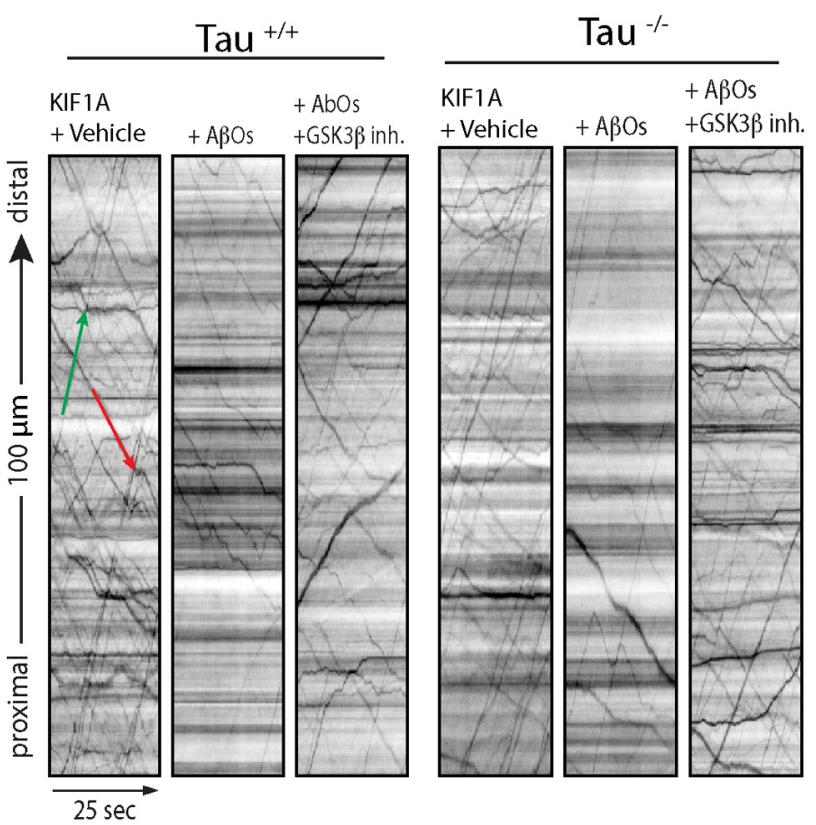

D KIF1A transport in $\mathrm{Tau}^{+/+}$neurons

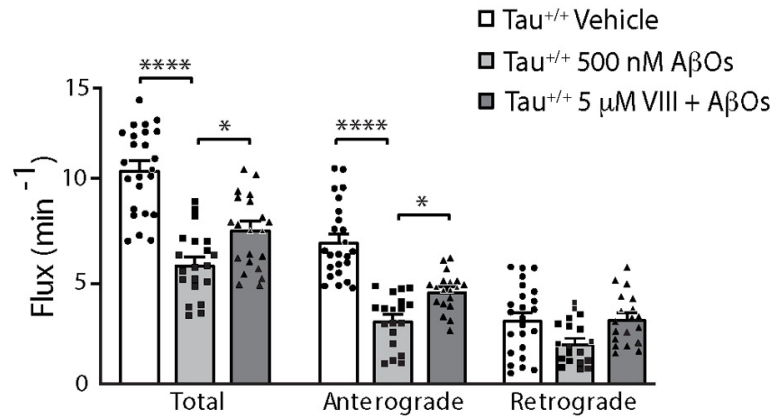

E KIF1A transport in $\mathrm{Tau}^{-/-}$neurons

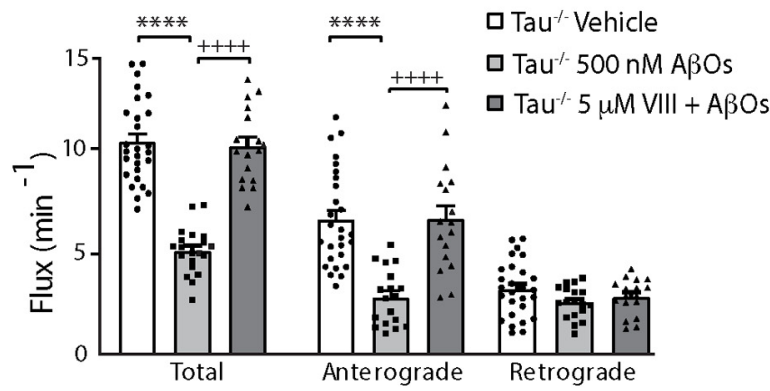

Figure 1. $\mathrm{A} \beta \mathrm{O}$ treatment blocks KIF1A transport in a GSK3 $\beta$-dependent and tau-independent manner. $\boldsymbol{A}$, Schematic of the timeline of experiments. $\boldsymbol{B}$, Representative image of soluble BFP and KIF1A-eGFP expressed in an A $\beta \mathrm{O}_{\text {-treated tau }}^{+/+}$neuron. A $\beta$ Os binds exclusively to dendrites and remain oligomeric after $18 \mathrm{~h}$ in culture. Arrows indicate axon; arrowheads indicate dendrites. $\boldsymbol{C}$, Effects of $A \beta$ Os and Inhibitor VIII treatment on KIF1A-GFP flux in tau ${ }^{+/+}$and tau ${ }^{-/-}$neurons. Representative kymographs comparing KIF1A-GFP transport in control and treated neurons. Lines with a positive slope represent anterograde transport (green); lines with a negative slope represent retrograde transport (red). $\boldsymbol{D}, \boldsymbol{E}$, Vesicle flux is significantly reduced in tau ${ }^{+/+}$and tau $^{-1-} \mathrm{A} \beta \mathrm{O}_{-}$ treated neurons and is restored by treatment with GSK3 $\beta$ Inhibitor VIII. All bar graphs display mean \pm SEM; at least 15 cells from three independent cultures were analyzed. Statistical significance was evaluated by one-way ANOVA with Tukey's post hoc 
continued

comparisons; $* p<0.05$ and $* * * * p<0.0001$ when compared with vehicle; $+p<0.05$ and $++++p<0.0001$ when compared with A $\beta$ Os; nonsignificant relations are not indicated. For complete transport statistics, see Table 1 and Extended Data Table 1-1.

Representative kymographs illustrate differences between KIF1A transport in control and $\mathrm{A} \beta \mathrm{O}$-treated neurons (Fig. 1C). $\mathrm{A} \beta \mathrm{O}$ treatment dramatically reduced anterograde KIF1A flux in both $\mathrm{tau}^{+/+}$and $\mathrm{tau}^{-/-}$neurons, indicating that tau is not required for $A \beta O$ disruption of KIF1A transport (Fig. 1D,E; Table 1). A $\beta$ Os also significantly decreased anterograde average velocity and run length in tau ${ }^{-1-}$ neurons. Retrograde movement of KIF1A, presumably driven by cytoplasmic dynein, was also decreased on $\mathrm{A} \beta \mathrm{O}$ treatment, although the effect in $\mathrm{tau}^{-/-}$ neurons was not statistically significant (Table 1). In all experiments, KIF1A transport parameters were similar to those previously reported for BDNF (Lo et al., 2011; Seifert et al., 2016; Bodakuntla et al., 2020), implying that changes in KIF1A motility are not attributed to overexpression artefacts. These results demonstrate that $A \beta O s$ reduce KIF1A motility independent of tau.

\section{GSK3 $\beta$ inhibition prevents KIF1A transport defects in A $\beta$ O-treated neurons}

Pharmacological inhibition and dominant negative mutations of GSK3 $\beta$ prevent BDNF transport defects induced by $A \beta O$ s (Ramser et al., 2013). This effect is observed in both $\mathrm{tau}^{+/+}$and $\mathrm{tau}^{-/-}$neurons, ruling out the possibility that tau activates PP1-GSK3 $\beta$ signaling to block transport, as reported previously for KIF5 in isolated squid axoplasm (Kanaan et al., 2011). Does GSK3 $\beta$ impair transport by reducing KIF1A motility in $A \beta O$-treated neurons, and does GSK3 $\beta$ require tau for this function? We incubated $\mathrm{tau}^{+/+}$and $\mathrm{tau}^{-/-}$neurons with $5 \mu \mathrm{M}$ Inhibitor VIII (a selective, cell-permeable, competitive blocker of GSK3 $\beta$; Bhat et al., 2003) for $30 \mathrm{~min}$ before $\mathrm{A} \beta \mathrm{O}$ treatment. Pretreatment with Inhibitor VIII prevented defects in KIF1A flux, velocity and run length (Fig. 1C-E; Table 1). Thus, consistent with previous findings for BDNF transport (Ramser et al., 2013), GSK3 $\beta$ mediates KIF1A transport impairment in $\mathrm{A} \beta \mathrm{O}$-treated neurons. This observed effect was comparable in both tau ${ }^{+/+}$and tau ${ }^{-/-}$ neurons (Fig. 1B; Table 1), demonstrating that GSK3 $\beta$ reduces KIF1A motility independent of tau.

\section{KIF1A interacts with GSK3 $\beta$ and is phosphorylated at a conserved GSK $3 \beta$ consensus site}

GSK3 $\beta$ has been shown to associate with kinesin-1 motor complexes (Morfini et al., 2002). To determine whether KIF1A interacts with GSK3 $\beta$, we generated cell lysates from mouse hippocampi and immunoprecipitated KIF1A using a specific monoclonal antibody (Fig. 2A). By immunoblotting, we found that GSK3 $\beta$ coimmunoprecipitates with input and KIF1A proteins, but not with negative control IgG proteins alone (Fig. 2A). This result indicates that KIF1A and GSK3 $\beta$ interact, either by forming a direct complex or by binding indirectly through scaffold proteins.
To identify specific residues of KIF1A that are phosphorylated by GSK3 $\beta$, we isolated KIF1A from 14month-old WT and Tg2576 (APP swe) mouse brains by immunoprecipitation and resolved the proteins by SDSPAGE. Following in-gel tryptic digestion, the resulting peptides were analyzed by sequential LC-MS/MS. Although immunoblots with pan-phospho-Ser and panphospho-Thr antibodies failed to detect any phosphoKIF1A immunoreactivity (Extended Data Fig. 1-1), we detected nine phosphopeptides in KIF1A (UniProtKB/ Swiss-Prot: Q6TA13), four of which conform to sequences targeted by kinases that are aberrantly activated in $A D$ including mitogen-activated protein kinase (MAPK), casein kinase II (CK2), and GSK3 $\beta$ (Fig. 2B,C; Extended Data Fig. 2-1; Maqbool et al., 2016; Cline et al., 2018). Because our analyses were not quantitative, we were unable to establish whether these phosphosites were more abundant in Tg2576 mice relative to WT mice. We compared high confidence KIF1A phosphopeptides in WT and Tg2576 mice using PhosphoRS and mapped them to specific sites within KIF1A functional domains (Fig. 2B). Phosphorylation within specific KIF1A sequences varied between genotypes; for example, S937, located within the presumed cargobinding peptide SGTS*QEELR, was phosphorylated (denoted by *) in Tg2576 mice but not detected in WT mice (Fig. 2D). However, S937 did not conform to an AD-related kinase motif according to the Phosida and Phosphonet databases. Based on these analyses, we focused on S402 (Fig. 2D) as it (1) is located between the neck-coil domain and the first coiled-coil domain and could therefore impact motor dimerization and/or motility (Fig. 2B; Al-Bassam et al., 2003; Hammond et al., 2009; Soppina et al., 2014), (2) conforms to a GSK3 $\beta$ consensus site, and (3) is conserved between zebrafish, mouse, rat, and human KIF1A proteins (Fig. 2E).

\section{GSK3 $\beta$ phosphorylates KIF1A at S402 in vitro}

To confirm phosphorylation of S402 and evaluate whether GSK3 $\beta$ can perform this modification, we developed a sensitive in vitro radiometric enzyme assay (Fig. 2F). We synthesized a WT KIF1A peptide containing S402 and a phosphomutant KIF1A peptide containing an alanine substitution at $\mathrm{S} 402$ (S402A). We then tested three different proline-directed kinases (CDK2, ERK2, and GSK $3 \beta$ ) for their ability to phosphorylate these peptides. Mutation of S402 nearly abolished the ability of GSK3 $\beta$ to phosphorylate the S402-containing peptide whereas the kinase activities of CDK2 and ERK2 were less impacted by the S402A mutation (Fig. 2F). These results confirm that $S 402$ is phosphorylated by GSK3 $\beta$ in vitro and support a plausible role for this residue in regulating KIF1A motility. 
A KIF1A binds GSK3 $\beta$ in cultured neurons

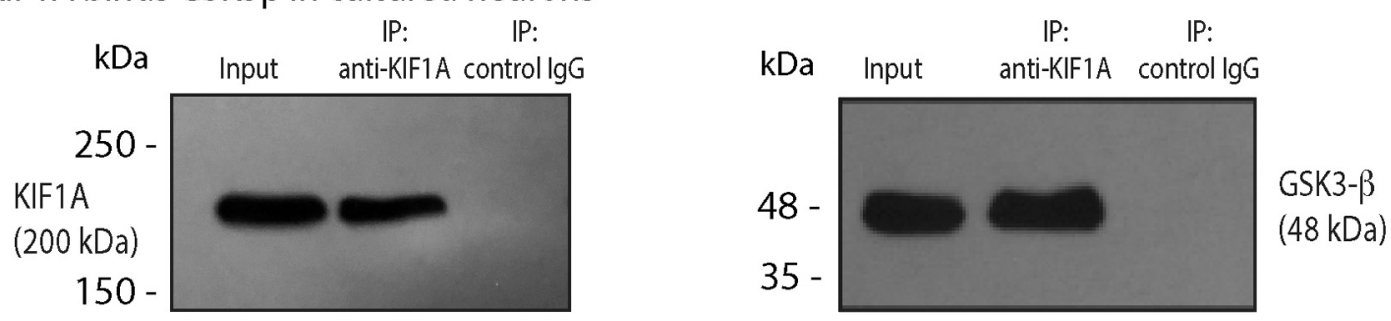

B Schematic of the domain organization of KIF1A

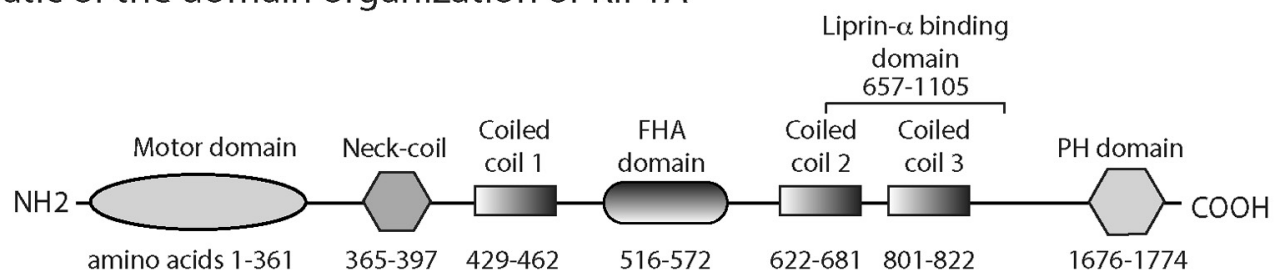

C Identification of phosphorylated peptides in KIF1A by mass spectrometry

\begin{tabular}{|c|c|c|c|c|}
\hline Sequence & $\underline{\mathrm{MH}+[\mathrm{Dal}}$ & $\frac{\text { Mascot Score }}{\text { WT/AD }}$ & $\frac{\text { Expected value }}{W T / A D}$ & Predicted Kinase \\
\hline 394-MTNALVGMS*PSSSL-406 & 2058.0 & $79 / 65$ & $1.9 \times 10^{-6} / 4.8 \times 10^{-5}$ & GSK3 $\beta$ \\
\hline 934-SGTS*0EELR-942 & 1086.4 & N.A/31 & N.A./0.045 & Casein kinase II \\
\hline 1326-VTGVYELSLCHVADAGS*PGMQR-1347 & 2444.1 & $63 / 45$ & $0.0001 / 0.008$ & ERK/MAPK \\
\hline 1535-PAS*PEPELLPELDSK-1546 & 1701.8 & $37 / 32$ & $0.03 / 0.089$ & GSK3 $\beta$ \\
\hline
\end{tabular}

D Identification of $\$ 402$ phosphopeptide

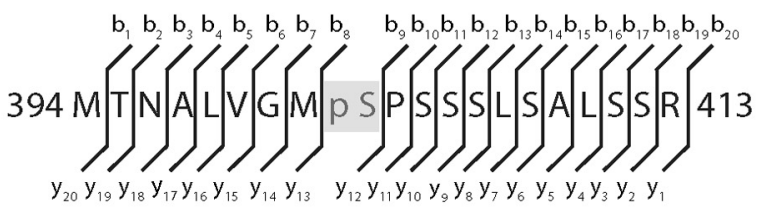

E Conservation of GSK3 $\beta$ consensus sequence

Mus 394 MTNALVGMSPSSSSLSALSSR 413

Rattus 403 MTNALVGMSPSSSLSALSSR 422

Danio 431 - TNAMTGM|SPSPSLSALSSR 449

Homo 394 MTNALVGMSSPSSLSALSSR 413

\section{F In vitro phosphorylation of the KIF1A MTNALVGMSPSSSL peptide}

\begin{tabular}{|l|l|l|l|l|}
\hline $\begin{array}{l}\text { Protein } \\
\text { Kinase }\end{array}$ & $\begin{array}{l}\text { KIF1A S402 } \\
\text { WT peptide } \\
\text { (counts/min) }\end{array}$ & $\begin{array}{l}\text { KIF1A S402A } \\
\text { MT peptide } \\
\text { (counts/min) }\end{array}$ & $\begin{array}{l}\text { Difference } \\
\text { (MT-WT)/WT }\end{array}$ & $\%$ Change \\
\hline GSK3 $\beta$ & 51,748 & 1,512 & 50,237 & $-97 \%$ \\
\hline CDK2 & 5,556 & 2,440 & 3,116 & $-56 \%$ \\
\hline ERK2 & 2,631 & 1,957 & 674 & $-26 \%$ \\
\hline
\end{tabular}

Figure 2. GSK3 $\beta$ phosphorylates KIF1A at several sites. A, A monoclonal antibody to KIF1A immunoprecipitated GSK3 $\beta$ from neuronal lysates. $\boldsymbol{B}$, Schematic of the domain organization of KIF1A (GenBank BAA0622.1). $\boldsymbol{C}$, Tandem mass spectroscopy on KIF1A isolated from WT and AD model mouse (APPswe; AD) brain identified four phosphopeptides which conform to sites targeted by kinases that are aberrantly activated in AD, such as MAPK, CK2, and GSK3 $\beta$. Serine 402 conforms to a GSK3 $\beta$ phosphorylation site according to Phosida (http://141.61.102.18/phosida/index.aspx) and Phosphonet (https://kinexus.ca). D, MS identification of the $b+$ and $y+$ ions that are the direct ( $\mathrm{N}$ to $\mathrm{C}$ terminus) and reverse ( $\mathrm{C}$ to $\mathrm{N}$ terminus) ion series obtained during collision-induced dissociation (also see Extended Data Fig. 1-1). E, Sequence comparison of the region surrounding Serine 402 between zebrafish, mouse, 
continued

rat, and human proteins. $\boldsymbol{F}$, The evaluation of three different proline-directed kinases (CDK2, ERK2, and GSK3 $\beta$ ) by radiometric assay indicates that GSK3 $\beta$ shows a strong preference for the KIF1A (S402) WT peptide over the A402 MT peptide in vitro.

\section{Point mutations of S402 do not alter KIF1A motility}

Does phosphorylation at S402 regulate KIF1A motility? We generated a non-phosphorylatable form of KIF1AeGFP by inducing a Ser-to-Ala point mutation (KIF1AS402A) at this site. Conversely, we induced a Ser-to-Glu point mutation to mimic GSK3 $\beta$ phosphorylation of KIF1A-eGFP at this site (KIF1A-S402E). We expressed these mutants in mouse hippocampal neurons and compared their motility to WT KIF1A by live cell imaging (Fig. $3 A$ ). Representative kymographs and quantification of transport parameters revealed no significant differences in flux, run length and velocity for KIF1A-S402A or KIF1AS402E relative to WT KIF1A (Fig. 3A; Table 2; Extended Data Table 1-1). These data imply that $S 402$ phosphorylation does not regulate KIF1A transport in hippocampal neurons. We next asked whether $\mathrm{A} \beta \mathrm{O}$-induced overactivation of GSK3 $\beta$ impairs KIF1A transport via phosphorylation at $\mathrm{S} 402$. We compared the motility of WT KIF1A-eGFP and KIF1A-S402A-eGFP in control and $\mathrm{A} \beta$ O-treated neurons (Fig. 3B; Table 2; Extended Data
Table 1-1). Kymograph analyses revealed that $A \beta O$ treatment similarly reduced the anterograde fluxes, velocities and run lengths of the WT and mutant motors, indicating that the alanine point mutation does not protect against KIF1A transport defects. Taken together, these results indicate that GSK3 $\beta$ does not regulate KIF1A motility through phosphorylation at S402A.

As an alternative explanation for this outcome, endogenous WT KIF1A may dimerize with mutant KIF1A monomers or preferentially bind to cargo, thus masking any effects of the mutations on KIF1A motility. To investigate the effects of S402A and S402E point mutations on KIF1A motility in the absence of endogenous KIF1A transport, we performed an inducible Golgi dispersion assay in COS7 cells (Engelke et al., 2016; Budaitis et al., 2019; Fig. $4 A$; Extended Data Figs. 4-1, 4-2). In this assay, Golgi-targeted kinesin motors cause the dispersion of the Golgi complex from its characteristic tightly-packed, perinuclear location to a phenotype consisting of small Golgiderived vesicles scattered throughout the cytoplasm

Table 1: Quantitative analysis of axonal KIF1A-GFP transport in $\operatorname{tau}^{+/+}$and tau $^{-/-}$neurons.

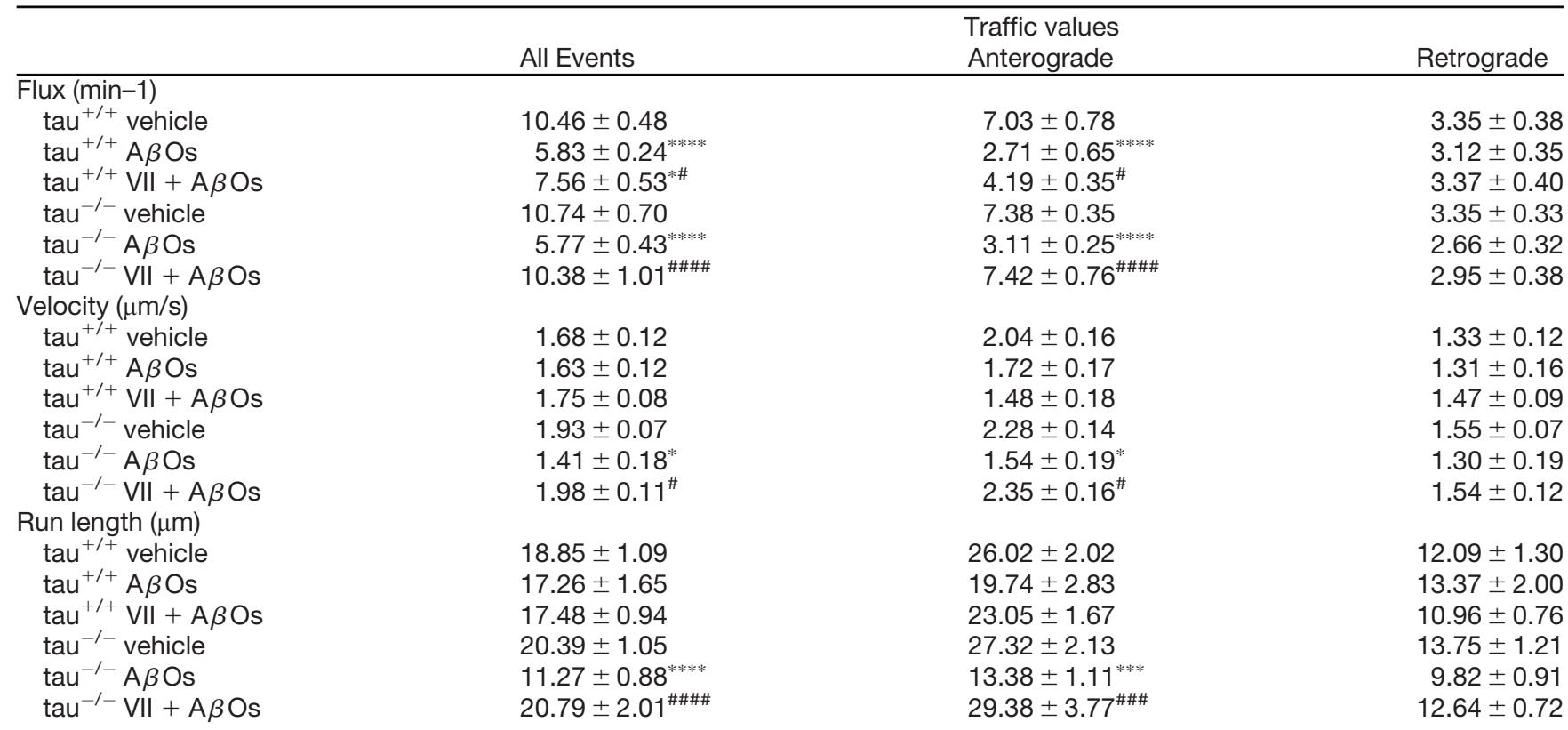

tau $^{+/+}$vehicle: $n=24$ kymographs (24 cells, 893 puncta).

tau $^{-/-}$vehicle: $n=27$ kymographs ( 27 cells, 1014 puncta).

$\mathrm{tau}^{+/+} \mathrm{A} \beta \mathrm{O}: n=18$ kymographs (19 cells, 432 puncta).

$\mathrm{tau}^{-1-} \mathrm{A} \beta$ O: $n=18$ kymographs (18 cells, 578 puncta).

$\mathrm{tau}^{+/+} \mathrm{VIII}+\mathrm{A} \beta \mathrm{O}: n=18$ kymographs (18 cells, 643 puncta)

$\mathrm{tau}^{-/-} \mathrm{VIII}+\mathrm{A} \beta \mathrm{O}: n=17$ kymographs (17 cells, 638 puncta).

${ }^{*} p<0.05$, when compared with vehicle.

** $p<0.01$, when compared with vehicle.

${ }_{* * * *}^{*} p<0.001$, when compared with vehicle.

***** $p<0.0001$, when compared with vehicle.

${ }^{\#} p<0.05$, when compared with $\mathrm{A} \beta$ Os.

$\# \#<0.01$, when compared with $A \beta$ Os.

$\# \# p<0.001$, when compared with $A \beta$ Os.

$\# \# \# p<0.0001$, when compared with $A \beta$ Os 
A Phosphomutants of $\mathrm{S} 402$ do not influence KIF1A anterograde motility in neurons
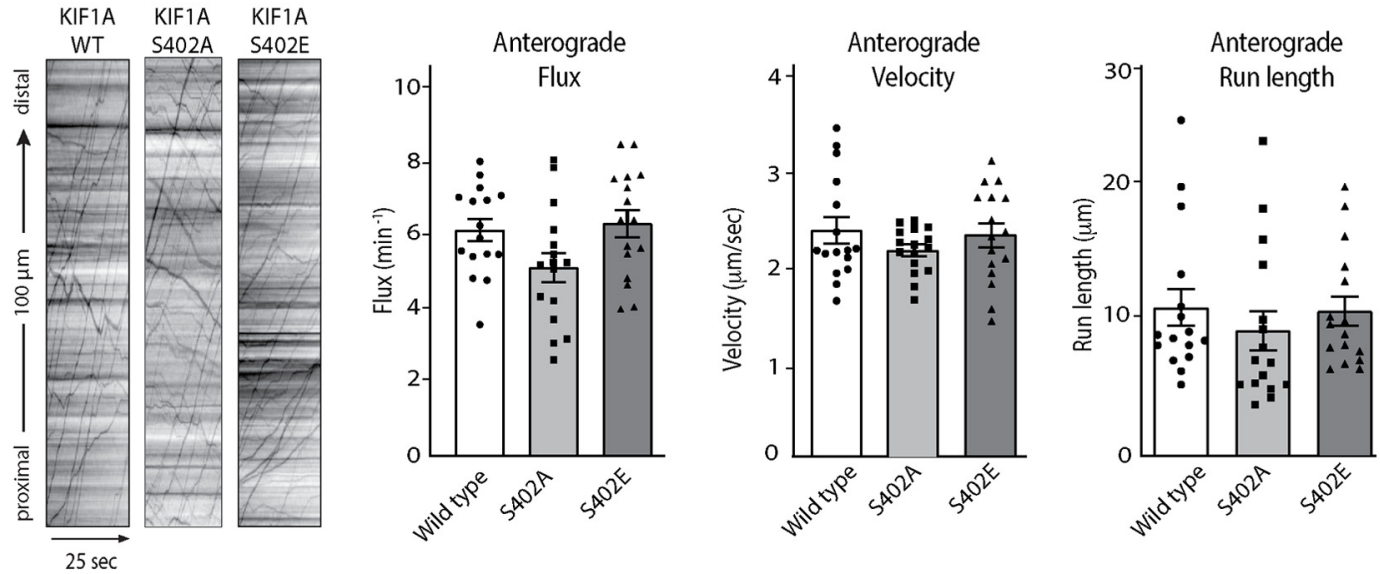

B The phosphomutant S402A does not prevent KIF1A anterograde motility defects in AßO-treated neurons
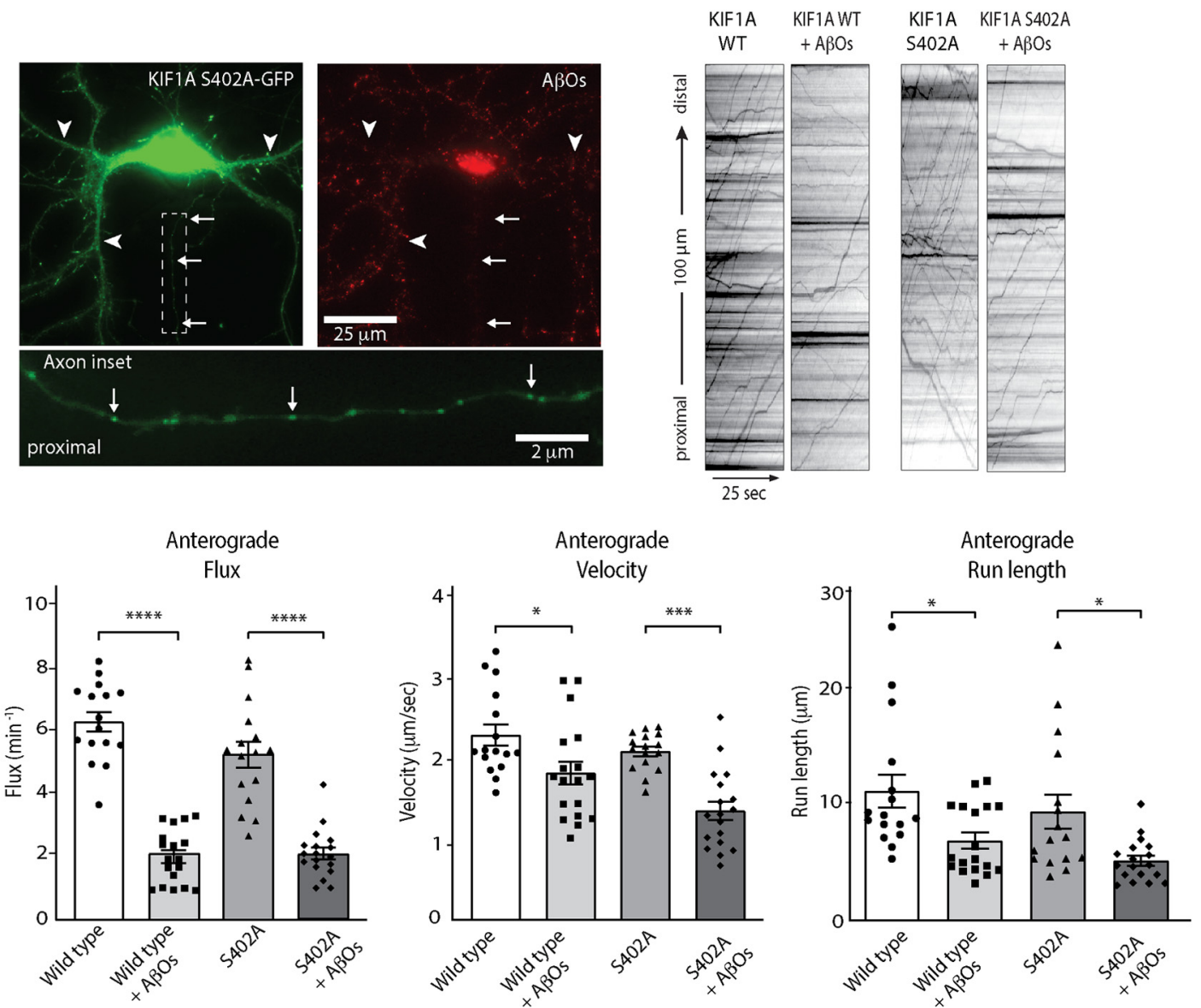

Figure 3. Phospho-mutants of Serine402 do not alter KIF1A-mediated transport. A, Representative kymographs comparing KIF1AeGFP WT, S402A, and S402E transport in WT neurons. Bar graphs display mean \pm SEM; at least 15 cells from three independent cultures were analyzed. Statistical significance was evaluated by one-way ANOVA with Tukey's post hoc comparisons; nonsignificant relations are not indicated. For complete statistics, see Table 2 and Extended Data Table 1-1. B, Representative image of KIF1A S402A-eGFP expressed in an A $\beta$ O-treated WT neuron. A $\beta$ Os bind exclusively to dendrites and remain oligomeric after $18 \mathrm{~h}$ in culture. Arrows indicate axon; arrowheads indicate dendrites. Representative kymographs comparing KIF1A-eGFP WT and S402A transport in control and $\mathrm{A} \beta \mathrm{O}$-treated neurons. Bar graphs display mean $\pm \mathrm{SEM}$; at least 15 cells from three independent cultures were analyzed. Statistical significance $(* p<0.05, * * p<0.01, * * * p<0.001, * * * *<0.0001)$ was evaluated by one-way ANOVA with Tukey's post hoc comparisons; nonsignificant relations are not indicated. For complete statistics, see Table 2 and Extended Data Table 1-1. 
Table 2: Quantitative analysis of axonal KIF1A-S402A and KIF1A-S402E transport in tau ${ }^{+/+}$neurons

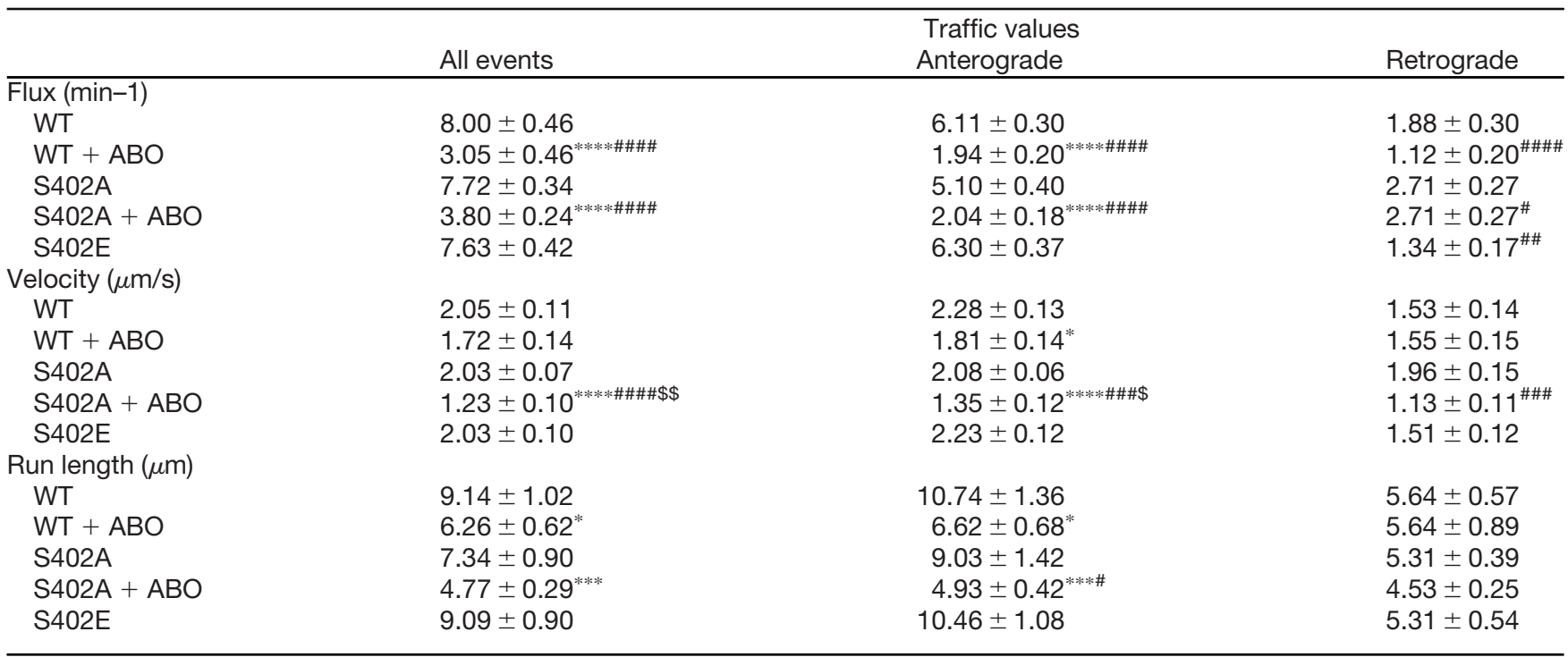

WT: $n=16$ kymographs (16 cells, 789 puncta).

S402A: $n=16$ kymographs (16 cells, 829 puncta).

WT + ABO: $n=18$ kymographs (18 cells, 381 puncta).

S402A + ABO: $n=18$ kymographs (18 cells, 430 puncta).

S402E: $n=16$ kymographs (16 cells, 743 puncta).

${ }^{*} p<0.05$, when compared with WT.

${ }_{* * *}^{*} p<0.01$, when compared with WT.

${ }_{* * * *} p<0.001$, when compared with WT.

****** $p<0.0001$, when compared with WT.

$\# p<0.05$, when compared with S402A.

$\# p<0.01$, when compared with S402A.

$\# \# p<0.001$, when compared with S402A

$\# \# \# p<0.0001$, when compared with S402A.

$\$ p<0.05$, when comparing $\mathrm{A} \beta \mathrm{O}$-treated conditions (significance denoted in $\mathrm{S} 402+\mathrm{A} \beta \mathrm{O}$ condition).

$\$ \$ p<0.01$, when comparing $\mathrm{A} \beta \mathrm{O}$-treated conditions (significance denoted in $\mathrm{S} 402+\mathrm{A} \beta \mathrm{O}$ condition).

$\$ \$ \$ p<0.001$, when comparing $\mathrm{A} \beta \mathrm{O}$-treated conditions (significance denoted in $\mathrm{S} 402+\mathrm{A} \beta \mathrm{O}$ condition).

$\$ \$ \$ p<0.0001$, when comparing $\mathrm{A} \beta \mathrm{O}$-treated conditions (significance denoted in $\mathrm{S} 402+\mathrm{A} \beta \mathrm{O}$ condition).

(Engelke et al., 2016). We used the rapamycin-induced dimerization of FRB and FKBP to drive the rapid recruitment of KIF1A motors to the Golgi surface and determined the effect on Golgi dispersion after 30 min of motor activity. This assay probes the ability of motors to drive transport in a cellular environment and requires motors capable of not only processive motility, but also sufficient force generation to oppose the Golgi-localized dynein that is responsible for the perinuclear clustering of this organelle (Corthésy-Theulaz et al., 1992; Burkhardt et al., 1997).

Because full-length KIF1A resides in an inactive, autoinhibited state, we first introduced a point mutation (V483N) that relieves the self-inhibition of motor activity (Huo et al., 2012; Yue et al., 2013; Soppina et al., 2014). Using this active version of full-length KIF1A, we then introduced point mutations that could abolish or mimic the phosphorylation state of the S402 residue. Using the rat KIF1A sequence, these mutations are S411A and S411E, respectively. WT and MT full-length KIF1A(V483N) motors were fused to mNeonGreen and a FRB domain, whereas the Golgi targeting sequence of the cis-Golgi resident protein GMAP210 was fused to monomeric red fluorescent protein (mRFP) and the FKBP domain (Engelke et al., 2016). Addition of rapamycin resulted in rapid recruitment of WT, S411A, and S411E motors to the Golgi surface and subsequent transport of Golgi particles to the cell periphery. No differences in Golgi dispersion were observed between the WT, S411A and S411E motors (Fig. 4A; Extended Data Fig. 4-2). These results indicate that the phosphorylation state of S411 does not impact the motility and force generation of KIF1A in this system. Alternatively, it is possible that the Ser-to-Glu mutation does not mimic KIF1A phosphorylation in this context (Dephoure et al., 2013).

\section{Discussion}

Impairment of axonal transport is an early pathologic event that leads to axonal degeneration and loss of synapse function in AD (Stokin et al., 2005; Minoshima and Cross, 2008; Gallagher et al., 2012; Sleigh et al., 2019). Soluble $\mathrm{A} \beta$ Os, a causative agent of AD (Cline et al., 2018), activate intracellular signaling cascades that trigger aberrant phosphorylation of many target proteins, including tau. Many studies have examined how tau hyperphosphorylation, microtubule destabilization, and cytoskeletal collapse impair transport (Mandelkow et al., 2003; Stokin and Goldstein, 2006; Cowan et al., 2010; Combs et al., 2019). However, subtler mechanisms of $\mathrm{A} \beta \mathrm{O}$-induced transport disruption that arise before neurotoxicity and that act directly on motor proteins to reduce their motility have received much less attention and have not been investigated in mammalian neurons. 
A
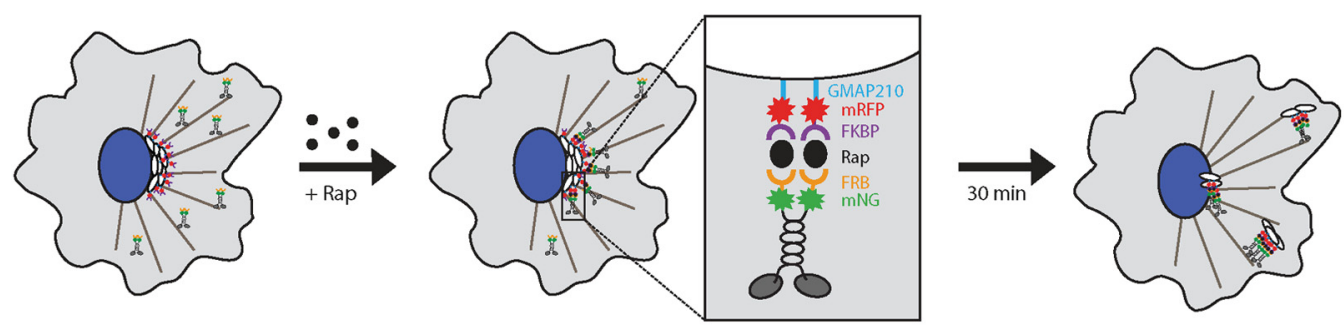

B
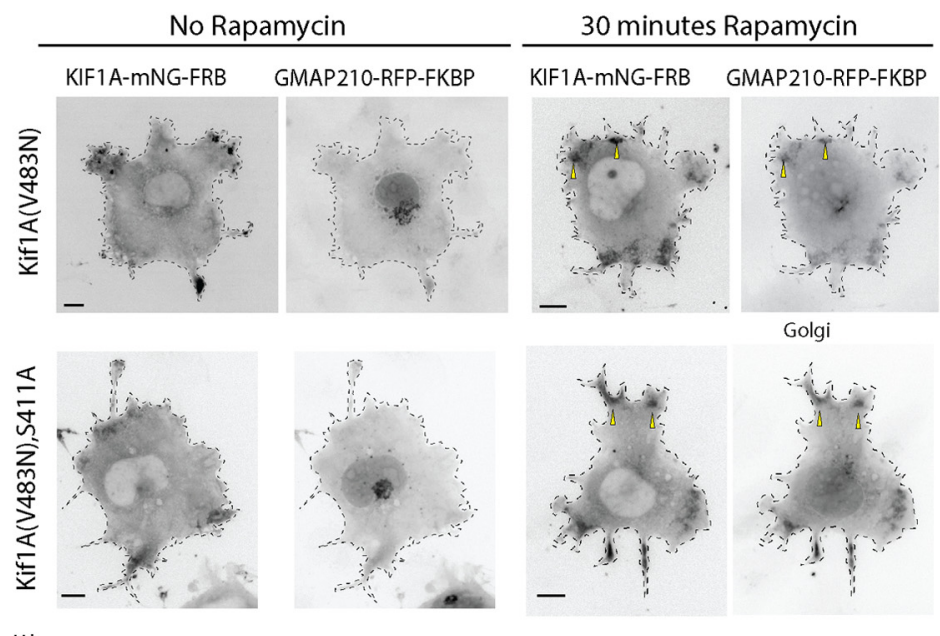

Golgi
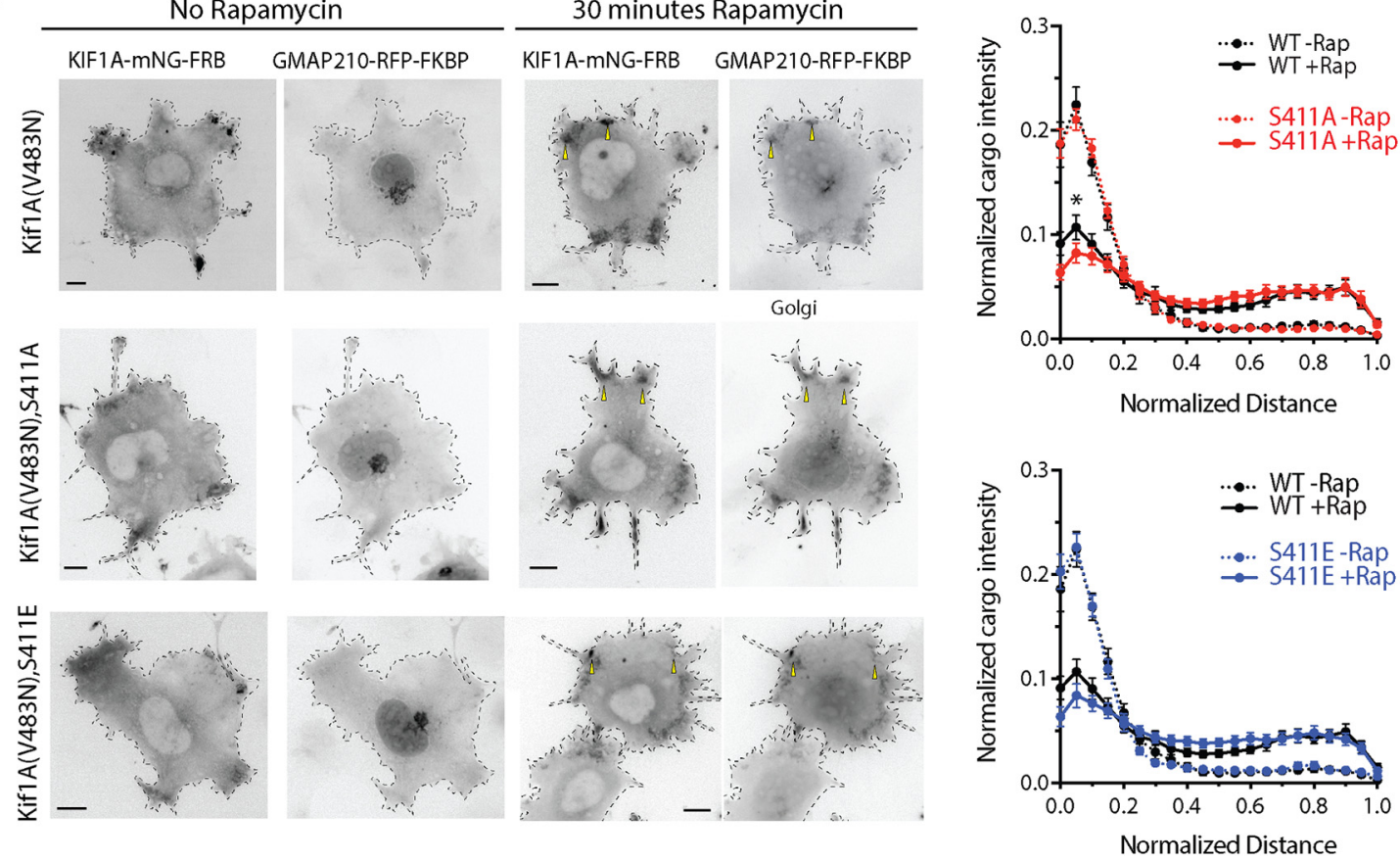

Figure 4. A phospho-mutant of S402 does not influence KIF1A activity in Golgi-dispersion assays. $\boldsymbol{A}$, Schematic of the inducible motor recruitment assay. A kinesin motor tagged with monomeric NeonGreen (mNG) and an FRB domain (KIF1A-mNG-FRB) is coexpressed with a Golgi targeting sequence (GMAP210) tagged with mRFP and FKBP domain (GMAP210-mRFP-FKBP) in COS7 cells. Addition of rapamycin (+Rap) causes heterodimerization of the FRB and FKBP domains and recruitment of motors to the cargo membrane. Recruitment of active motors drives cargo dispersion to the cell periphery. B, COS7 cells expressing WT, S411A, or S411E versions of full-length active (V483N) KIF1A-mNG-FRB together with GMAP210-mRFP-2xFKBP were treated with ethanol vehicle (no rapamycin, left panels) or with $44 \mathrm{~nm}$ rapamycin (middle panels). After $30 \mathrm{~min}$, the cells were fixed and stained with an antibody to the Golgi marker giantin (data not shown) and DAPI (data not shown). Representative images of the KIF1A-mNG-FRB (KIF1A motor) and GMAP210-mRFP-2xFKBP (Golgi marker) channels are shown in inverse grayscale. Yellow arrowheads indicated examples of dispersed Golgi particles. Scale bars: $10 \mu \mathrm{m}$. The Golgi distribution in the giantin channel was quantified and the data are displayed as the fluorescence intensity of Golgi particles on the $y$-axis and the normalized distance on the $x$-axis $(0.0=$ edge of nucleus, $1.0=$ plasma membrane). WT -Rap (dotted black lines), $n=26$ cells; WT + Rap (solid black lines), $n=31$ cells; S411A -Rap (dotted red line), $n=30$ cells; S411A + Rap (solid red line), $n=29$ cells; S411E -Rap (dotted blue line), $n=27$ cells; S411E +Rap (solid blue line), $n=28$ cells across two independent experiments. Statistical differences in mean cargo intensity between WT and MT motors were calculated at each binned distance and for each condition (-Rap and +Rap) by using a two-tailed unpaired Student's $t$ test; $* p<0.05$. For complete statistical analysis, see Extended Data Figure 4-2.

Here, through direct assessment of trafficking at high spatial and temporal resolution in mouse hippocampal neurons, we demonstrate that $\mathrm{A} \beta$ Os impair KIF1A motility independent of tau (Fig. 1). These results are consistent with previous findings that $A \beta$ Os impair motility of the KIF1A cargo protein BDNF and that this defect is independent of tau (Ramser et al., 2013). We also demonstrate that pharmacological inhibition of GSK3 $\beta$ prevented these transport defects (Fig. 1), motivating us to investigate whether KIF1A motility is dysregulated by phosphorylation. By MS, we identified nine phosphorylation sites on KIF1A, four of which are targeted by kinases associated with $A D$, including GSK3 $\beta$ (Fig. 2). We discovered that $S 402$, located proximal to the neck-coil domain of KIF1A, conforms to a highly conserved GSK3 $\beta$ consensus site (Fig. 2). Using an in vitro kinase assay, we 
confirmed that S402 is indeed phosphorylated by GSK3 $\beta$ (Fig. 2). Finally, we tested whether a phosphomimic of S402 could modulate KIF1A motility in cultured neurons and in a Golgi dispersion assay using COS-7 cells that lacked endogenous KIF1A. Unfortunately, in both experimental systems, no significant differences in transport properties were observed between WT and mutant KIF1A (Figs. 3 and 4). From these findings, we conclude that GSK3 $\beta$ impairs KIF1A transport independent of tau but likely does not achieve this effect by phosphorylating KIF1A at S402.

Traditionally, axonal transport defects were viewed as a consequence of tau hyperphosphorylation and aggregation, tau-induced kinase activation, microtubule dissolution, and axonal dystrophy during the advanced stages of disease progression (Mandelkow et al., 2003; Stokin and Goldstein, 2006; LaPointe et al., 2009; Morfini et al., 2009; Kanaan et al., 2011). However, transport defects can occur independent of tau and before overt morphologic decline and cell death, suggesting that early transport defects might play a causal role in AD pathogenesis (Pigino et al., 2003; Lazarov et al., 2007; Stokin et al., 2008; Goldstein, 2012; Rodrigues et al., 2012; Ramser et al., 2013). Recent reports indicate that overactivation of GSK $3 \beta$ contributes to many pathologic hallmarks of $A D$ including increased $\mathrm{A} \beta$ production, tau hyperphosphorylation, and impaired learning and memory (Maqbool et al., 2016). Data from our present study suggest, pending identification of the specific phosphorylation sites, that the pathologic activation of GSK3 $\beta$ can impair transport by earlier, subtler mechanisms that involve inhibitory phosphorylation of motor proteins. Such mechanisms of GSK3 $\beta$-dependent motor protein inhibition have been characterized previously in invertebrate models of AD. As a negative regulator of axonal transport in Drosophila, active GSK3 $\beta$ binds and phosphorylates kinesin-1 and reduces the number of motors bound to microtubules (Weaver et al., 2013; Banerjee et al., 2018). Alternatively, kinesin motor activity can be inhibited by cargo detachment; in isolated squid axoplasm treated with $\mathrm{A} \beta \mathrm{O}$ s, GSK3 $\beta$ phosphorylates kinesin light chain-2, promoting motor-cargo dissociation and impairing transport (Morfini et al., 2002). Interestingly, and perhaps paradoxically, we found a significant effect on KIF1A run lengths and velocity in the tau ${ }^{-1-}$ neurons treated with $A \beta O$ s (Fig. 1; Table 1). $A \beta O$ s dysregulate a number of intracellular cascades, including those active toward tau (Cline et al., 2018). It is possible that in the absence of a tau-kinase substrate, these kinases (or phosphatases) aberrantly target regulatory sites on KIF1A that govern processivity akin to the phosphorylation of the motor domain on kinesin-1 in Drosophila (Weaver et al., 2013; Banerjee et al., 2018) and KIF5C at S176 (DeBerg et al., 2013). Our study is congruent with those reports and, additionally, is first to show that GSK3 $\beta$ impairs KIF1A motility in a mammalian primary culture model of AD (Fig. 1).

From the nine phosphorylation sites on KIF1A revealed by MS (Fig. 2; Extended Data Fig. 1-1), we chose to investigate S402. This phosphopeptide has also been identified by large scale phosphoproteomic analyses in mouse and human brain (Ullah et al., 2016). However, we found that point mutations of S402 do not regulate KIF1A transport in two cell-based assays (Figs. 3 and 4). As these are negative results, it is possible that the S402E mutation does not fully mimic the addition of a phosphate at this site in the WT motor. It is also possible that single amino acid changes meant to prevent or mimic phosphorylation events are insufficient to alter motor behavior. Indeed, another study found that AMP kinase-dependent phosphorylation of kinesin light chain-1 (KLC1) at S517/S520 does not affect motor function (McDonald et al., 2010). However, several reports demonstrate that increased phosphorylation at a single site is sufficient to impair motor protein motility. Phosphorylation of KIF5C at S176 by JNK weakens motor-microtubule interactions and/or reduces force output (DeBerg et al., 2013; Padzik et al., 2016). Cargo binding, which is required to activate motor proteins, is also disrupted by phosphorylation. MAP kinase phosphorylates KLC1 at S460 to reduce binding and trafficking of calsyntenin-1 (Vagnoni et al., 2011). Moreover, S460 phosphorylation is increased in AD, disrupting axonal transport and promoting amyloidogenic processing of the amyloid precursor protein (APP; Mórotz et al., 2019). Therefore, it may be that phosphorylation at multiple sites synergistically impairs motor motility. Future studies on KIF1A could investigate whether GSK3 $\beta$ and/ or other kinases phosphorylate different sites within the motor and cargo-binding domains, and whether mechanisms of cargo dissociation and microtubule detachment converge to impair KIF1A motility.

\section{References}

Abney JR, Meliza CD, Cutler B, Kingma M, Lochner JE, Scalettar BA (1999) Real-time imaging of the dynamics of secretory granules in growth cones. Biophys J 77:2887-2895.

Al-Bassam J, Cui Y, Klopfenstein D, Carragher BO, Vale RD, Milligan RA (2003) Distinct conformations of the kinesin Unc104 neck regulate a monomer to dimer motor transition. J Cell Biol 163:743-753.

Banerjee R, Rudloff Z, Naylor C, Yu M, Gunawardena S (2018) The presenilin loop region is essential for glycogen synthase kinase 3 $\beta$ (GSK3 $\beta$ ) mediated functions on motor proteins during axonal transport. Hum Mol Genet 27:2986-3001.

Barkus RV, Klyachko O, Horiuchi D, Dickson BJ, Saxton WM (2008) Identification of an axonal kinesin-3 motor for fast anterograde vesicle transport that facilitates retrograde transport of neuropeptides. Mol Biol Cell 19:274-283.

Bhat R, Xue Y, Berg S, Hellberg S, Ormö M, Nilsson Y, Radesäter $A C$, Jerning $E$, Markgren PO, Borgegård T, Nylöf $M$, GiménezCassina A, Hernández F, Lucas JJ, Díaz-Nido J, Avila J (2003) Structural insights and biological effects of glycogen synthase kinase 3-specific inhibitor AR-A014418. J Biol Chem 278:4593745945.

Bloom GS (2014) Amyloid- $\beta$ and tau: the trigger and bullet in Alzheimer disease pathogenesis. JAMA Neurol 71:505-508.

Bodakuntla S, Schnitzler A, Villablanca C, Gonzalez-Billault C, Bieche I, Janke C, Magiera MM (2020) Tubulin polyglutamylation is a general traffic-control mechanism in hippocampal neurons. $J$ Cell Sci 133:jcs241802.

Brady ST, Morfini GA (2017) Regulation of motor proteins, axonal transport deficits and adult-onset neurodegenerative diseases. Neurobiol Dis 105:273-282.

Budaitis BG, Jariwala S, Reinemann DN, Schimert KI, Scarabelli G, Grant BJ, Sept D, Lang MJ, Verhey KJ (2019) Neck linker docking 
is critical for Kinesin-1 force generation in cells but at a cost to motor speed and processivity. Elife 8:e44146.

Burkhardt JK, Echeverri CJ, Nilsson T, Vallee RB (1997) Overexpression of the dynamitin (p50) subunit of the dynactin complex disrupts dynein-dependent maintenance of membrane organelle distribution. J Cell Biol 139:469-484.

Cline EN, Bicca MA, Viola KL, Klein WL (2018) The amyloid- $\beta$ oligomer hypothesis: beginning of the third decade. J Alzheimers Dis 64:S567-S610.

Combs B, Mueller RL, Morfini G, Brady ST, Kanaan NM (2019) Tau and axonal transport misregulation in tauopathies. Adv Exp Med Biol 1184:81-95.

Corthésy-Theulaz I, Pauloin A, Pfeffer SR (1992) Cytoplasmic dynein participates in the centrosomal localization of the Golgi complex. J Cell Biol 118:1333-1345.

Cowan CM, Bossing T, Page A, Shepherd D, Mudher A (2010) Soluble hyper-phosphorylated tau causes microtubule breakdown and functionally compromises normal tau in vivo. Acta Neuropathol 120:593-604.

DeBerg HA, Blehm BH, Sheung J, Thompson AR, Bookwalter CS, Torabi SF, Schroer TA, Berger CL, Lu Y, Trybus KM, Selvin PR (2013) Motor domain phosphorylation modulates kinesin-1 transport. J Biol Chem 288:32612-32621.

Decker H, Lo KY, Unger SM, Ferreira ST, Silverman MA (2010) Amyloid-beta peptide oligomers disrupt axonal transport through an NMDA receptor-dependent mechanism that is mediated by glycogen synthase kinase 3beta in primary cultured hippocampal neurons. J Neurosci 30:9166-9171.

Dephoure N, Gould KL, Gygi SP, Kellogg DR (2013) Mapping and analysis of phosphorylation sites: a quick guide for cell biologists. Mol Biol Cell 24:535-542.

Engelke MF, Winding M, Yue Y, Shastry S, Teloni F, Reddy S, Blasius TL, Soppina P, Hancock WO, Gelfand VI, Verhey KJ (2016) Engineered kinesin motor proteins amenable to small-molecule inhibition. Nat Commun 7:11159.

Ferreira ST, Lourenco MV, Oliveira MM, De Felice FG (2015) Soluble amyloid-beta oligomers as synaptotoxins leading to cognitive impairment in Alzheimer's disease. Front Cell Neurosci 9:191.

Gallagher JJ, Zhang X, Ziomek GJ, Jacobs RE, Bearer EL (2012) Deficits in axonal transport in hippocampal-based circuitry and the visual pathway in APP knock-out animals witnessed by manganese enhanced MRI. Neuroimage 60:1856-1866.

Gan KJ, Silverman MA (2015) Dendritic and axonal mechanisms of $\mathrm{Ca} 2+$ elevation impair BDNF transport in $\mathrm{A} \beta$ oligomer-treated hippocampal neurons. Mol Biol Cell 26:1058-1071.

Gan KJ, Silverman MA (2016) Imaging organelle transport in primary hippocampal neurons treated with amyloid- $\beta$ oligomers. Methods Cell Biol 131:425-451.

Gibbs KL, Greensmith L, Schiavo G (2015) Regulation of axonal transport by protein kinases. Trends Biochem Sci 40:597-610.

Goldstein LS (2012) Axonal transport and neurodegenerative disease: can we see the elephant? Prog Neurobiol 99:186-190.

Hammond JW, Cai D, Blasius TL, Li Z, Jiang Y, Jih GT, Meyhofer E, Verhey KJ (2009) Mammalian kinesin-3 motors are dimeric in vivo and move by processive motility upon release of autoinhibition. PLoS Biol 7:e72.

Hung CO, Coleman MP (2016) KIF1A mediates axonal transport of BACE1 and identification of independently moving cargoes in living SCG neurons. Traffic 17:1155-1167.

Huo L, Yue Y, Ren J, Yu J, Liu J, Yu Y, Ye F, Xu T, Zhang M, Feng W (2012) The CC1-FHA tandem as a central hub for controlling the dimerization and activation of kinesin-3 KIF1A. Structure 20:15501561.

Kaech S, Banker G (2006) Culturing hippocampal neurons. Nat Protoc 1:2406-2415.

Kanaan NM, Morfini GA, LaPointe NE, Pigino GF, Patterson KR, Song Y, Andreadis A, Fu Y, Brady ST, Binder LI (2011) Pathogenic forms of tau inhibit kinesin-dependent axonal transport through a mechanism involving activation of axonal phosphotransferases. $\mathrm{J}$ Neurosci 31:9858-9868.
Kondo M, Takei Y, Hirokawa N (2012) Motor protein KIF1A is essential for hippocampal synaptogenesis and learning enhancement in an enriched environment. Neuron 73:743-757.

Kwinter D, Silverman MA (2009) Live imaging of dense-core vesicles in primary cultured hippocampal neurons. J Vis Exp (27):1140.

Lambert MP, Barlow AK, Chromy BA, Edwards C, Freed R, Liosatos M, Morgan TE, Rozovsky I, Trommer B, Viola KL, Wals P, Zhang C, Finch CE, Krafft GA, Klein WL (1998) Diffusible, nonfibrillar ligands derived from Abeta1-42 are potent central nervous system neurotoxins. Proc Natl Acad Sci USA 95:6448-6453.

Lambert MP, Velasco PT, Chang L, Viola KL, Fernandez S, Lacor PN, Khuon D, Gong Y, Bigio EH, Shaw P, De Felice FG, Krafft GA, Klein WL (2007) Monoclonal antibodies that target pathological assemblies of Abeta. J Neurochem 100:23-35.

LaPointe NE, Morfini G, Pigino G, Gaisina IN, Kozikowski AP, Binder LI, Brady ST (2009) The amino terminus of tau inhibits kinesin-dependent axonal transport: implications for filament toxicity. J Neurosci Res 87:440-451.

Lazarov O, Morfini GA, Pigino G, Gadadhar A, Chen X, Robinson J, Ho H, Brady ST, Sisodia SS (2007) Impairments in fast axonal transport and motor neuron deficits in transgenic mice expressing familial Alzheimer's disease-linked mutant presenilin 1. J Neurosci 27:7011-7020.

Lee JR, Shin H, Ko J, Choi J, Lee H, Kim E (2003) Characterization of the movement of the kinesin motor KIF1A in living cultured neurons. J Biol Chem 278:2624-2629.

Lo KY, Kuzmin A, Unger SM, Petersen JD, Silverman MA (2011) $\mathrm{KIF} 1 \mathrm{~A}$ is the primary anterograde motor protein required for the axonal transport of dense-core vesicles in cultured hippocampal neurons. Neurosci Lett 491:168-173.

Mandelkow EM, Stamer K, Vogel R, Thies E, Mandelkow E (2003) Clogging of axons by tau, inhibition of axonal traffic and starvation of synapses. Neurobiol Aging 24:1079-1085.

Maqbool M, Mobashir M, Hoda N (2016) Pivotal role of glycogen synthase kinase-3: a therapeutic target for Alzheimer's disease. Eur $\mathrm{J}$ Med Chem 107:63-81.

Mariga A, Mitre M, Chao MV (2017) Consequences of brain-derived neurotrophic factor withdrawal in CNS neurons and implications in disease. Neurobiol Dis 97:73-79.

McDonald A, Fogarty S, Leclerc I, Hill EV, Hardie DG, Rutter GA (2010) Cell-wide analysis of secretory granule dynamics in three dimensions in living pancreatic beta-cells: evidence against a role for AMPK-dependent phosphorylation of KLC1 at Ser517/Ser520 in glucose-stimulated insulin granule movement. Biochem Soc Trans 38:205-208.

Minoshima S, Cross D (2008) In vivo imaging of axonal transport using MRI: aging and Alzheimer's disease. Eur J Nucl Med Mol Imaging 35 [Suppl 1]:S89-S92.

Miranda CJ, Braun L, Jiang Y, Hester ME, Zhang L, Riolo M, Wang H, Rao M, Altura RA, Kaspar BK (2012) Aging brain microenvironment decreases hippocampal neurogenesis through Wnt-mediated survivin signaling. Aging Cell 11:542-552.

Morfini G, Szebenyi G, Elluru R, Ratner N, Brady ST (2002) Glycogen synthase kinase 3 phosphorylates kinesin light chains and negatively regulates kinesin-based motility. EMBO J 21:281-293.

Morfini GA, Burns M, Binder LI, Kanaan NM, LaPointe N, Bosco DA, Brown RH Jr, Brown H, Tiwari A, Hayward L, Edgar J, Nave KA, Garberrn J, Atagi Y, Song Y, Pigino G, Brady ST (2009) Axonal transport defects in neurodegenerative diseases. J Neurosci 29:12776-12786.

Mórotz GM, Glennon EB, Greig J, Lau DHW, Bhembre N, Mattedi F, Muschalik N, Noble W, Vagnoni A, Miller CCJ (2019) Kinesin light chain-1 serine-460 phosphorylation is altered in Alzheimer's disease and regulates axonal transport and processing of the amyloid precursor protein. Acta Neuropathol Commun 7:200.

Padzik A, Deshpande P, Hollos P, Franker M, Rannikko EH, Cai D, Prus $P$, Mågård $M$, Westerlund $N$, Verhey $K J$, James $P$, Hoogenraad CC, Coffey ET (2016) KIF5C S176 phosphorylation regulates microtubule binding and transport efficiency in mammalian neurons. Front Cell Neurosci 10:57. 
Pigino G, Morfini G, Pelsman A, Mattson MP, Brady ST, Busciglio J (2003) Alzheimer's presenilin 1 mutations impair kinesin-based axonal transport. J Neurosci 23:4499-4508.

Ramser EM, Gan KJ, Decker H, Fan EY, Suzuki MM, Ferreira ST, Silverman MA (2013) Amyloid- $\beta$ oligomers induce tau-independent disruption of BDNF axonal transport via calcineurin activation in cultured hippocampal neurons. Mol Biol Cell 24:2494-2505.

Rodrigues EM, Weissmiller AM, Goldstein LS (2012) Enhanced $\beta$-secretase processing alters APP axonal transport and leads to axonal defects. Hum Mol Genet 21:4587-4601.

Seifert B, Eckenstaler R, Rönicke R, Leschik J, Lutz B, Reymann K, Lessmann V, Brigadski T (2016) Amyloid-beta induced changes in vesicular transport of BDNF in hippocampal neurons. Neural Plast 2016:4145708.

Sleigh JN, Rossor AM, Fellows AD, Tosolini AP, Schiavo G (2019) Axonal transport and neurological disease. Nat Rev Neurol 15:691-703.

Soppina V, Norris SR, Dizaji AS, Kortus M, Veatch S, Peckham M, Verhey KJ (2014) Dimerization of mammalian kinesin-3 motors results in superprocessive motion. Proc Natl Acad Sci USA 111:5562-5567.

Stokin GB, Goldstein LS (2006) Axonal transport and Alzheimer's disease. Annu Rev Biochem 75:607-627.

Stokin GB, Lillo C, Falzone TL, Brusch RG, Rockenstein E, Mount SL, Raman R, Davies P, Masliah E, Williams DS, Goldstein LS (2005) Axonopathy and transport deficits early in the pathogenesis of Alzheimer's disease. Science 307:1282-1288.
Stokin GB, Almenar-Queralt A, Gunawardena S, Rodrigues EM, Falzone T, Kim J, Lillo C, Mount SL, Roberts EA, McGowan E, Williams DS, Goldstein LS (2008) Amyloid precursor protein-induced axonopathies are independent of amyloid-beta peptides. Hum Mol Genet 17:3474-3486.

Ullah S, Lin S, Xu Y, Deng W, Ma L, Zhang Y, Liu Z, Xue Y (2016) dbPAF: an integrative database of protein phosphorylation in animals and fungi. Sci Rep 6:23534.

Vagnoni A, Rodriguez L, Manser C, De Vos KJ, Miller CC (2011) Phosphorylation of kinesin light chain 1 at serine 460 modulates binding and trafficking of calsyntenin-1. J Cell Sci 124:1032-1042.

Weaver C, Leidel C, Szpankowski L, Farley NM, Shubeita GT, Goldstein LS (2013) Endogenous GSK-3/shaggy regulates bidirectional axonal transport of the amyloid precursor protein. Traffic 14:295-308.

Yonekawa Y, Harada A, Okada Y, Funakoshi T, Kanai Y, Takei Y, Terada S, Noda T, Hirokawa N (1998) Defect in synaptic vesicle precursor transport and neuronal cell death in KIF1A motor protein-deficient mice. J Cell Biol 141:431-441.

Yue Y, Sheng Y, Zhang HN, Yu Y, Huo L, Feng W, Xu T (2013) The CC1-FHA dimer is essential for KIF1A-mediated axonal transport of synaptic vesicles in C. elegans. Biochem Biophys Res Commun 435:441-446.

Zhang L, Trushin S, Christensen TA, Tripathi U, Hong C, Geroux RE, Howell KG, Poduslo JF, Trushina E (2018) Differential effect of amyloid beta peptides on mitochondrial axonal trafficking depends on their state of aggregation and binding to the plasma membrane. Neurobiol Dis 114:1-16. 